\title{
Taxonomy, Evolution, and Biogeography of the Rhodniini Tribe (Hemiptera: Reduviidae)
}

\author{
Carolina Hernández ${ }^{1}\left(\mathbb{D}\right.$, João Aristeu da Rosa ${ }^{2}$, Gustavo A. Vallejo ${ }^{3} \oplus$, Felipe Guhl ${ }^{4}(\mathbb{D}$ and \\ Juan David Ramírez ${ }^{1, *(D)}$
}

1 Grupo de Investigaciones Microbiológicas-UR (GIMUR), Departamento de Biología, Facultad de Ciencias Naturales, Universidad del Rosario, Bogotá 111211, Colombia; dianac.hernandez@urosario.edu.co

2 Universidade Estadual Paulista (UNESP), Faculdade de Ciências Farmacêuticas, Araraquara, Sao Paulo 01000, Brazil; joaoaristeu@gmail.com

3 Laboratorio de Investigaciones en Parasitología Tropical (LIPT), Universidad del Tolima, Ibagué 730001, Colombia; gvallejo@ut.edu.co

4 Centro de Investigaciones en Microbiología y Parasitología Tropical (CIMPAT), Departamento de Ciencias Biológicas, Facultad de Ciencias, Universidad de los Andes, Bogotá 111711, Colombia; fguhl@uniandes.edu.co

* Correspondence: juand.ramirez@urosario.edu.co

Received: 27 January 2020; Accepted: 4 March 2020; Published: 11 March 2020

check for updates

\begin{abstract}
The Triatominae subfamily includes 151 extant and three fossil species. Several species can transmit the protozoan parasite Trypanosoma cruzi, the causative agent of Chagas disease, significantly impacting public health in Latin American countries. The Triatominae can be classified into five tribes, of which the Rhodniini is very important because of its large vector capacity and wide geographical distribution. The Rhodniini tribe comprises 23 (without $R$. taquarussuensis) species and although several studies have addressed their taxonomy using morphological, morphometric, cytogenetic, and molecular techniques, their evolutionary relationships remain unclear, resulting in inconsistencies at the classification level. Conflicting hypotheses have been proposed regarding the origin, diversification, and identification of these species in Latin America, muddying our understanding of their dispersion and current geographic distribution. Clarifying these factors can help for the design of vector control strategies. The aim of this review is to depict the different approaches used for taxonomy of the Rhodniini and to shed light on their evolution and biogeography.
\end{abstract}

Keywords: Triatominae; Chagas Disease; Rhodnius; Psammolestes; evolution; taxonomy; Rhodniini; biogeography

\section{Introduction}

Chagas disease is caused by the protozoan parasite and hemoflagellate Trypanosoma cruzi. This pathology mainly affects Latin American countries, where there are an estimated 6-8 million people infected and causes approximately 50,000 deaths per year [1]. The parasite can be transmitted by insect vectors, blood transfusion, vertical transmission, organ transplantation, laboratory accidents, and oral route [1,2]. The major transmission mechanism is via contact between humans and the feces of infected insects of the subfamily Triatominae (Hemiptera: Reduviidae) [1-4]. Human infection occurs accidentally during urbanization and environmental imbalances (deforestation and habitat loss) which cause triatomine insects infected with the parasite to invade human dwellings [3-7].

In the Triatominae subfamily, 151 extant and three fossil species have been reported and classified into five tribes according to their morphological, biological, and ecological characteristics $[8,9]$. Most subfamily diversity is restricted to Latin America, where 135 species have been described [10]. The 
Rhodniini tribe is one of the most diverse and has 23 described species ( 20 of the genus Rhodnius and three of Psammolestes). Within the genus Rhodnius, some species are important vectors of T. cruzi [3,8,11,12], and some have been found to have the capacity to produce metacyclic trypomastigotes of T. rangeli in their salivary glands [13-20].

Rhodnius prolixus is one of the main vectors of Chagas disease. Its wide geographic distribution (extending from Central America through the Andean countries and the Amazon basin), its capacity for domiciliation, its high dispersion, and its strong vector capacity are a threat to the future of vector control programs [21-23]. In addition to R. prolixus, three species within the Rhodniini tribe have been found domiciled: Rhodnius ecuadoriensis in the northern zone of Peru and Ecuador, Rhodnius stali in Bolivia, and Rhodnius pallescens in Panama. Rhodnius prolixus, R. ecuadoriensis, R. pallescens, and R. stali are infected with T. cruzi at prevalence rates of 12.0-82.0\% [24-26], 10.0-42.0\% [15,27,28], 42.0-87.4\% [24,29-33], and 7.7\% [34], respectively. Additionally, R. neglectus and R. nasutus are epidemiologically relevant species in Brazil, where they often invade and colonize human environments [7,35-37].

Although the taxonomy of the genus Rhodnius has been widely studied, there are controversies regarding the number of species, the classification of these species into groups, and the phylogenetic relationships and monophyletic status of these groups. These have arisen from the conflicting results of morphometric analyses, cytogenetic analyses, and analyses of isoenzyme markers and molecular markers $[8,12,38]$. There is also controversy regarding the paraphyly of two genera belonging to the Rhodniini tribe (Rhodnius and Psammolestes): although morphological differences are present, other techniques used for taxonomic analysis group Psammolestes with Rhodnius [8,38].

The objective of this review is to describe the current state of knowledge of the phylogenetic and biogeographical relationships among the species of the Rhodniini tribe and to highlight the need for new studies to develop a more comprehensive understanding of the systematics of these species.

\section{The Rhodninii Tribe: the Current Taxonomy}

The Rhodniini tribe is composed of two genera: the genus Rhodnius consisting of 20 species and the genus Psammolestes consisting of three species (Table 1). Initially, it was proposed that the three species belonging to the genus Psammolestes should be grouped into a tribe called Psammolestini given their marked morphological differences compared with the genus Rhodnius [39]. Later the two genera were grouped into the Rhodniini tribe, based mostly on the presence of tuberosities posterior to the eyes and bearing in mind that they represented mostly arboreal species with the exception of some of the Rhodnius $[8,40,41]$. The Rhodniini tribe has been extensively studied due to its epidemiological importance and wide geographical distribution. Additionally, members of the genus Rhodnius have been classified into three groups—pictipes, pallescens, and prolixus—based on geographical distribution, biogeography, and morphology. Initially these groups were called lineages; however, since their monophyletic origin has been questioned, the term group is currently preferred [8].

Table 1. Genera and species of the Rhodniini tribe.

\begin{tabular}{|c|c|c|}
\hline Genus & Group & Species \\
\hline \multirow{3}{*}{ Rhodnius } & pictipes & $\begin{array}{c}\text { R. amazonicus, } R . \text { brethesi, } R \text {. paraensis, R. pictipes, } R . \text { stali, } \\
\text { R. zeledoni }\end{array}$ \\
\hline & pallescens & R. colombiensis, R. ecuadoriensis, R. pallescens \\
\hline & prolixus & $\begin{array}{l}\text { R. barretti, } R . \text { dalessandroi, } R . \text { domesticus, } R \text {. milesi, } R . \\
\text { marabaensis, } R \text {. montenegrensis, } R \text {. nasutus, } R \text {. neglectus, } R \text {. } \\
\quad \text { neivai, } R \text {. prolixus, } R \text {. robustus, } R \text {. taquarussuensis * }\end{array}$ \\
\hline Psammolestes & & $P$. arthuri, $P$. coreodes, $P$. tertius \\
\hline
\end{tabular}




\section{Geographical Distribution of Members of the Rhodniini Tribe}

The Rhodniini tribe has a wide geographical distribution ranging from Central America to the Southern Cone (Figure 1A). The distribution of species richness within the tribe is unimodal, with a greater number of species identified towards the northern hemisphere at low latitudes and some species identified in the southern hemisphere, reaching latitudes of $30^{\circ}$ south [10].

A.

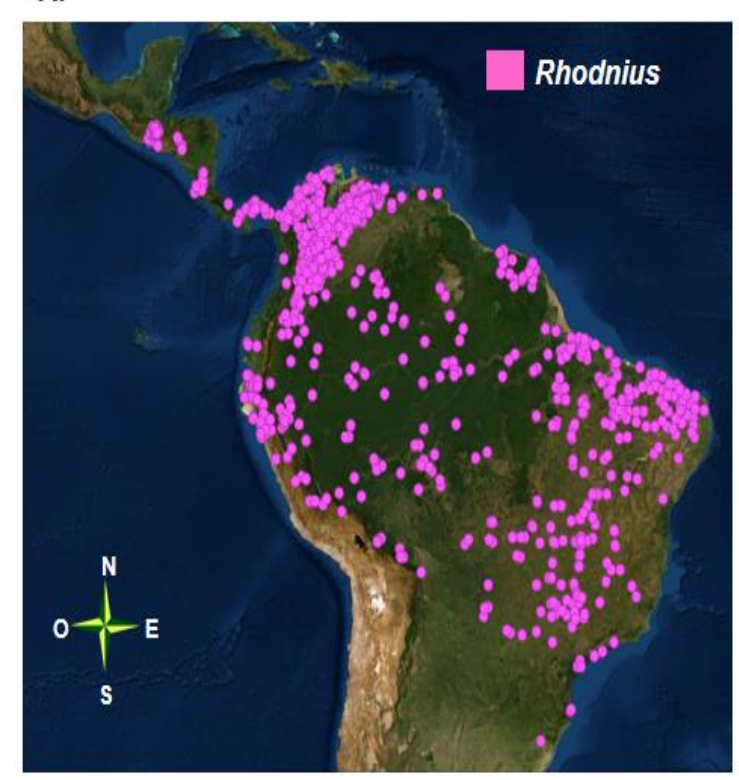

B.

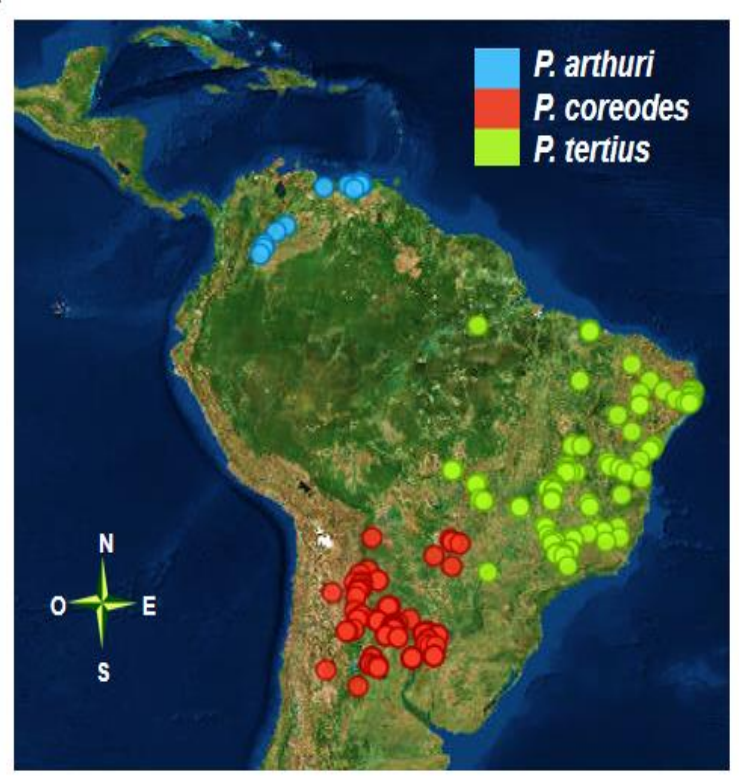

Figure 1. Geographical distribution of the Rhodniini tribe (A) Geographical distribution of the genus Rhodnius (B) Geographical distribution of species within the genus Psammolestes. Each point corresponds to geographical locations where individuals of each species were identified, these points were reported in several studies and compilated in a database by Ceccarelli and colleagues. This database was used to reconstruct the maps in Orange software (v.3.24.1) [42].

The genus Psammolestes has an interesting geographical distribution, and each of the three species with this genus has a distinct distribution (Figure 1B). Members of this genus are found mainly in bird nests (Furnariidae and Psittacidae), although they have also been identified in palm trees $[43,44]$. Psammolestes arthuri is distributed in Colombia and Venezuela. In Colombia, it has been described in the departments of the Orinoco region and in Venezuela it has been described in 15 different states, mainly in the plains region [42,45]. The range of P. tertius extends widely in Brazil, mainly in the Caatinga and much of the Cerrado [44]. Psammolestes coreodes is distributed in the Gran Chaco, and is widely distributed throughout 11 provinces in Argentina as well as in Paraguay, Bolivia, and the state of Mato Grosso do Sul, in the Brazilian Cerrado [46].

The geographical distribution of the genus Rhodnius is wider, covering part of Central America and a large part of South America. Geographical distribution is one of the criteria used for classification of the previously mentioned groups: species of the group pallescens (trans-Andean) are distributed to the west of the Andes mountain range (Figure 2A), while species of the groups prolixus and pictipes (cis-Andean) are distributed east of the Andes and the Amazon region (Figure 2B,C) [8]. 
A.

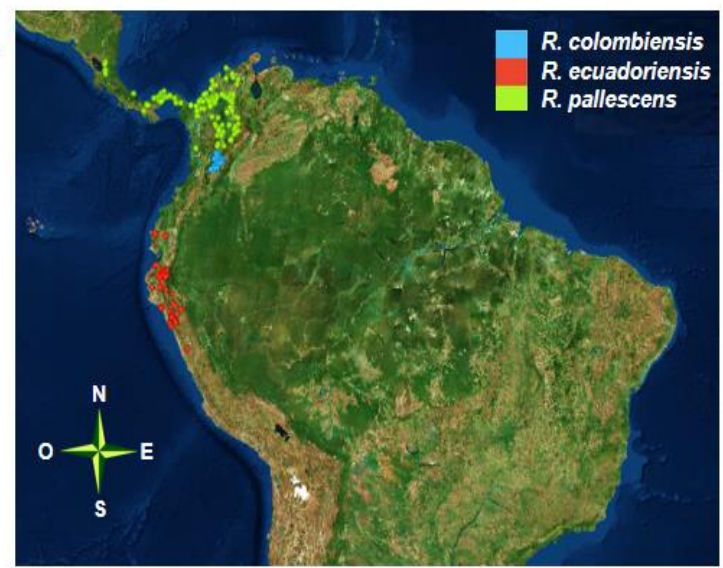

B.
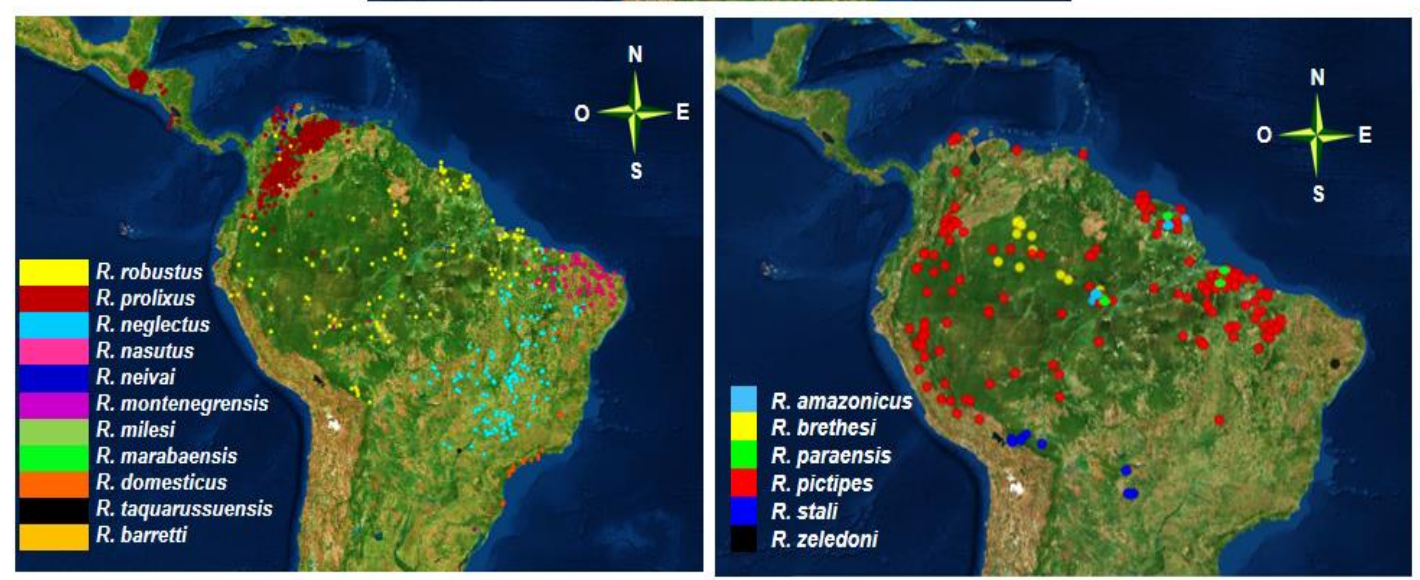

C.

Figure 2. Distribution of species within the genus Rhodnius (A) Geographical distribution of species of the trans-pallescens group (B) Geographical distribution of species of the cis-prolixus group (C) Geographical distribution of species of the cis-pictipes group. Each point corresponds to geographical locations where individuals of each species were identified, these points were reported in several studies and compilated in a database by Ceccarelli and colleagues. This database was used to reconstruct the maps in Orange software (v.3.24.1) [42].

In the trans-pallescens group, all species are associated mainly with palms. The species with the widest geographical distribution in this group is $R$. pallescens, whose range extends into western Colombia, Panama, Costa Rica, Belize, and Nicaragua. R. pallescens is mainly associated with wine palms (Attalea butyracea) and oil (Elaeis oleifera) and has also been found in human dwellings, mainly in Panama $[47,48]$. R. ecuadoriensis is distributed in Ecuador and northern Peru and is strongly associated with human dwellings and with the palm Phytelephas aequatorialis in northern Ecuador, although it has also been identified in squirrel nests [28,47,49]. Finally, Rhodnius colombiensis is found in Colombia in the departments of Cundinamarca and Tolima, where it is also associated with the wine palm A. butyracea $[10,46,47,50,51]$.

The cis-prolixus group has the largest number of species and the largest geographical distribution of the three groups. Among the species of this group, R. prolixus is the best studied given its epidemiological importance and has been reported in countries of Central America as well as in Colombia and Venezuela $[12,43,46,52]$. As a major vector, $R$. prolixus is mainly found in domestic habitats, although jungle populations associated with palms have also been identified in Colombia and Venezuela [22,52]. Control programs in Central America have achieved both the interruption of T. cruzi transmission and the direct elimination of $R$. prolixus, drastically decreasing its distribution in Mesoamerican countries [40,53-56]. However, the presence of $R$. prolixus has been reported again in Mexico, in 2019 [57]. Additionally, some reports of R. prolixus in Bolivia, Brazil, Ecuador, Guyana, 
French Guiana, Panama, and Suriname were erroneous, probably due to confusion with $R$. robustus and in central Brazil with $R$. neglectus [10,58-62].

Another species within the prolixus group with a wide geographical distribution is $R$. robustus, whose range extends through Bolivia, Brazil, Colombia, Ecuador, French Guiana, Peru, Venezuela, and Suriname $[10,46,60,61]$. Five cryptic species (I-V) have been reported within this species: R. robustus I is found in Venezuela, while $R$. robustus II, III, and IV are distributed in the Amazon region spanned by the previously mentioned countries [61]. There are reports of species of the prolixus group outside of Brazil with more restricted ranges such as $R$. barretti and $R$. dalessandroi. $R$. barretti has been identified from different palms in the Napo ecoregion in the western Amazon, the region that encompasses the lowlands of eastern Ecuador and the adjacent areas of southern Colombia (south of the Caguán River), and the north from Peru [63]. Rhodnius dalessandroi has only been reported once in the department of Meta, Colombia [46,56].

The other species of the prolixus group are exclusively Brazilian. R. neglectus, R. nasutus, and $R$. domesticus are associated with the Brazilian ecoregions, $R$. neglectus is dispersed in the Cerrado and São Paulo state, R. nasutus in the arid regions of the Caatinga, and R. domesticus in the Atlantic forest. The first two species are found in palm trees and bird nests, while $R$. domesticus has been identified in bromeliads $[7,40,46,56,64]$. Rhodnius montegrensis has been found in two states of Brazil (Acre and Rondonia), while the ranges of R. milesi and R. marabaensis are limited to the state of Pará [65-67]. Rhodnius taquarussuensis n.sp. was initially proposed as a new species in Taquarussu (Mato Grosso do $\mathrm{Sul})$, but is currently considered a phenotypic form of R. neglectus [68,69].

Finally, the cis-pictipes group also has a wide geographic distribution. Within this group, R. pictipes has the widest geographical distribution of the entire Rhodniini tribe, extending throughout the Amazon basin (north and northwest of South America) in association with different palms. There have been reports of this species in Belize, Bolivia, Brazil, Colombia, Ecuador, Guyana, French Guiana, Peru, Suriname, Trinidad, and Venezuela (Figure 2C) $[10,40,46,60]$. The species with the next-widest distribution is $R$. brethesi, which is characterized by its association with the palm Leopoldina piassaba. The geographical distribution of this species extends to the Amazon basin in Colombia and Venezuela and the states of Para and Amazonas in Brazil [10,40,46,47,52,56,70].

Rhodnius stali is distributed in Brazil (Matto Grosso and Acre) and in several provinces of Bolivia, where it is associated with $A$. phalerata and is also found in human dwellings, primarily in Alto Bení (Bolivia) $[40,43,44,46,71]$. Rhodnius neivai is found on fallen tree trunks and in the crowns of the llanera palm (Copernicia tectorium) in Colombia and Venezuela $[47,56]$. Rhodnius amazonicus and R. paraensis are distributed in French Guiana and Brazil, where R. paraensis has been found in nests of arboreal rodents of the genus Echimys $[11,56,58]$. Finally, R. zeledoni was identified in a single report in the northeast of Brazil in the state of Sergipe [72].

\section{Taxonomic and Phylogenetic Studies of the Rhodniini Tribe}

The taxonomy and systematics of the Rhodniini tribe are complex. Efforts to classify the species of this tribe date back to the middle of the 18 th century, at which time R. prolixus, R. pictipes, and R. nasutus were first described. The most studied species is $R$. prolixus. Since its life cycle is relatively short compared with other triatomines, it has been used as a biological model for studies of the physiology and biology of the Triatominae [40]. In addition to morphological studies, cytogenetic, isoenzymatic, and molecular studies have all been applied to members of the Rhodniini tribe, providing different levels of resolution in the study of their specific relationships [40]. However, it should be noted that many of these studies have focused only on the differentiation or analysis of selected species and few attempted to clarify the relationships among all members of the tribe.

\subsection{Morphological Studies}

Taxonomic classification of the Rhodniini tribe was initially based on morphological similarities and differences between species and included biogeographical aspects. However, one of the main limitations, 
especially for the Rhodniini tribe, was low morphological variability between species $[8,41,73]$. The characters that have been classically used for classification of the Rhodniini tribe were generally size, color, or patterns of coloration in some parts of the insect, and aspects of the cuticle. Additionally, various characters are used at the level of the head, thorax, abdomen, and legs [41,74]. New characters have been proposed for identification of triatomines and have been applied to the Rhodniini tribe. These include the spermatheca, geometric morphometry of the wings, morphology of abdominal segments IX and X, coloration of the salivary glands, and morphology of the genitalia. Use of some of these new characters has enabled differentiation at the level of the tribe presence of nitrophorins that confer red coloration to the salivary glands of the Rhodniini tribe and the morphometry of the wings as well as at the intra-specific level of the genus Rhodnius (Form of the female genitalia) [74-78].

The inclusion of the genera Rhodnius and Psammolestes within the Rhodniini tribe was based on their mainly arboreal behavior and the presence of post-ocular tuberosities in members of both genera. The latter feature is exclusive to both genera [41]. Between the two genera, differences can be observed in the morphology of the head and the shape of the femurs. However, these characters were insufficient to accurately reconstruct a cladogram and investigate relationships between the genera (Figure 3) $[8,40,41]$.

A.
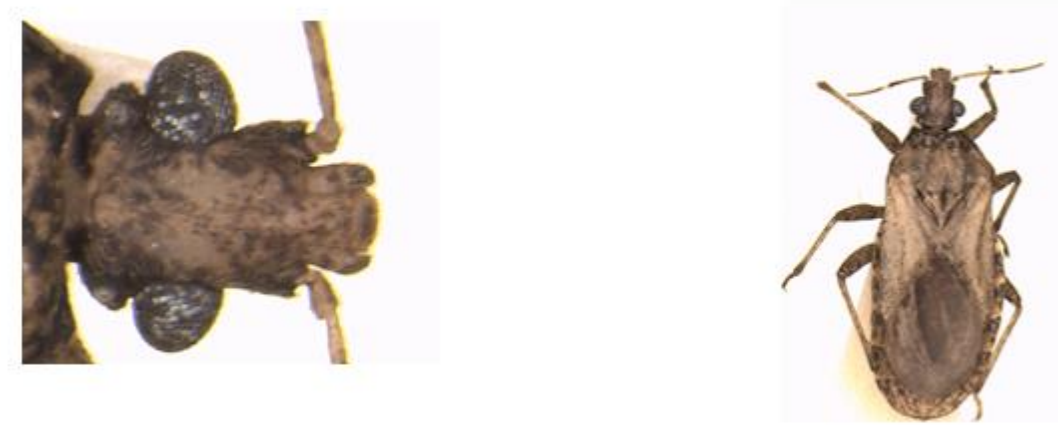

B.
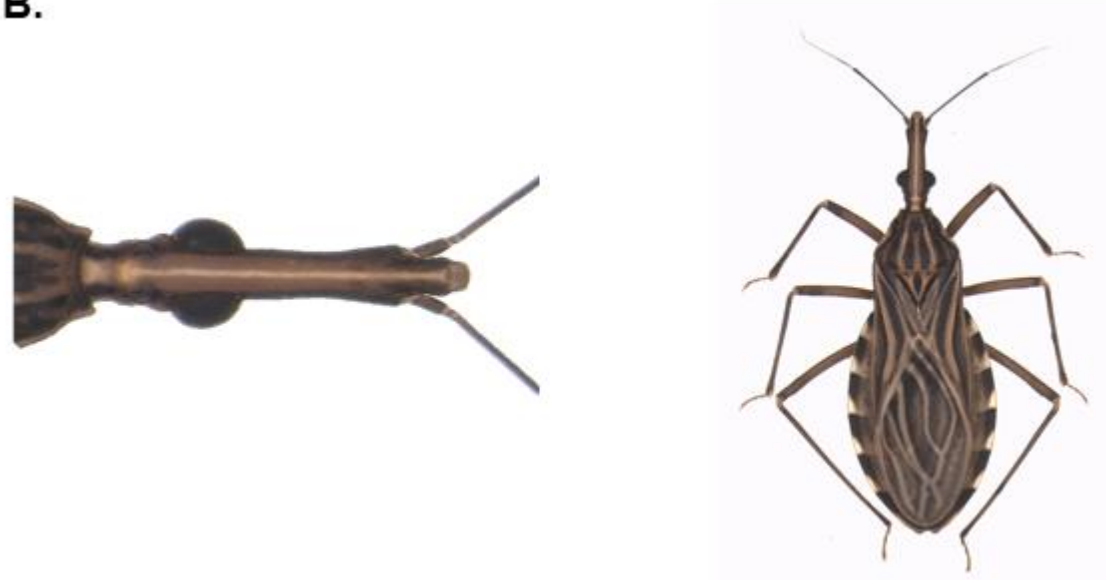

Figure 3. Morphology of the head and complete body of genera of the Rhodniini tribe (A) Morphology of the genus Psammolestes (P. tertius) (B) Morphology of the genus Rhodnius (R. prolixus). The images were supplied by João Aristeu da Rosa (Co-author of this manuscript).

In the genus Psammolestes, the morphology of the head, antennae, pronotum, genitalia of the males, and their phallosoma represent characters enabling identification of the three described species [24]. In the case of the genus Rhodnius, morphological characters enabling species differentiation are very few and can be affected by phenotypic variability. These characters also vary in association 
with environmental changes yielding minor changes, which have been postulated to contribute to misclassification of species $[12,38,40,46]$.

The cis-prolixus group presents very little morphological variability (Figure 4A). Thus, the feasibility of species identification using morphological characters has been questioned. There have even been mistakes in distinguishing $R$. prolixus and $R$. robustus, because the most useful difference between them for classification lies in the coloration of the hind tibiae of nymphs IV and V $[41,61,79,80]$. Additionally, the identity of some species within the prolixus group has been questioned: (i) $R$. milesi and $R$. taquarussuensis due to their similarity with $R$. neglectus; (ii) $R$. montenegrensis and $R$. marabaensis due to similarities with the cryptic species $R$. robustus II and III, respectively and (iii) $R$. dalessandroi due to morphological similarities with $R$. brethesi (group pictipes) and $R$. robustus $[38,41,56,68,69]$. With respect to coloration patterns, $R$. neivai differs from other species in the group by its dark coloration, and a dark black morphotype of $R$. nasutus has been identified with size variations in accordance with the environment and colonized palm trees $[41,81,82]$.

A.

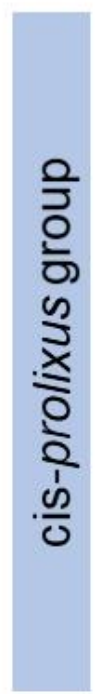

B.

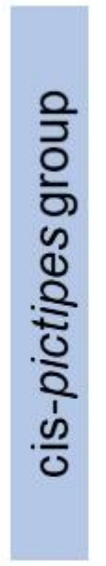

\section{R. prolixus}

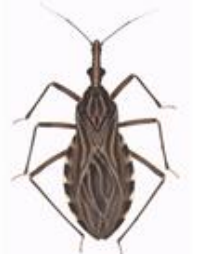

$R$. montenegrensis

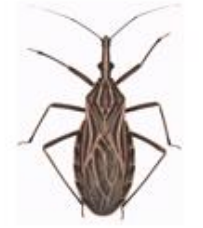

R. amazonicus

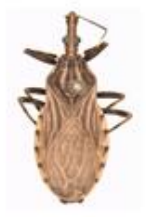

R. pictipes

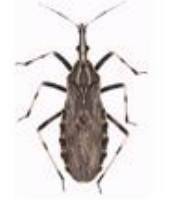

R. robustus

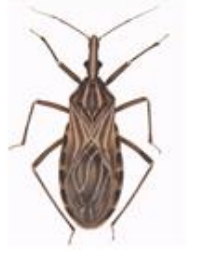

R. milesi
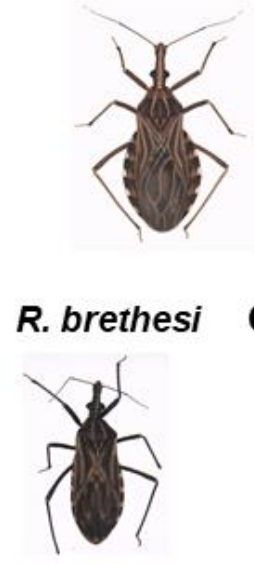

R. stali

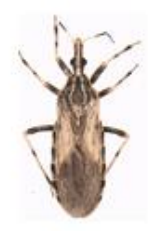

R. neglectus

R. nasutus

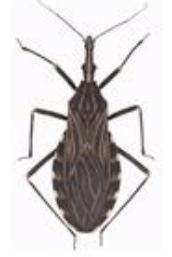

R. domesticus

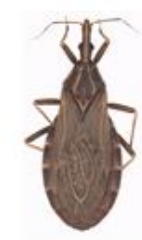

C.

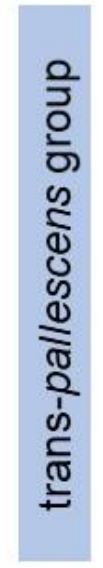

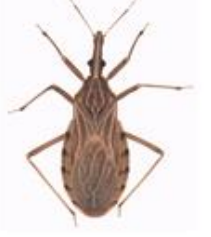

R. neivai

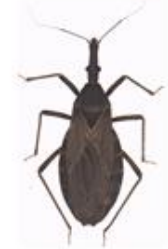

R. colombiensis

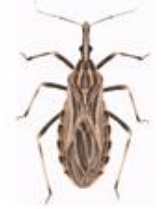

R. ecuadoriensis

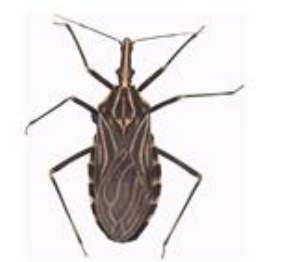

R. marabaensis

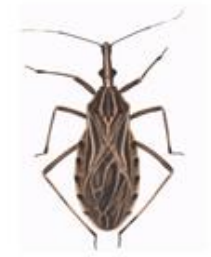

Figure 4. Morphology of species within the genus Rhodnius. (A) cis-prolixus group species, R. taquarussuensis is currently considered a phenotypic form of R. neglectus, $\left(^{*}\right)$ indicates that $R$. nasutus has two isoforms (B) cis-pictipes group species (C) trans-pallescens group species. The images were obtained by João Aristeu da Rosa. The morphology of R. barreti can be observed in Abad-Franch et al., 2013 [63] and R. dalessandroi, R. paraensis and R. zeledoni can be found in Jurberg et al., 2014 [83].

More morphological differences are observed between members of the group pictipes (Figure 4B). The validity of the species $R$. amazonicus has been questioned because it was documented in only a single original report and differences with respect to R. pictipes were not evident [41]. However, 
subsequent reports in French Guiana and Breves, Pará, Brazil reaffirmed the characteristics observed in the original report $[11,58,84]$. Rhodnius zeledoni was also described in only a single report and is thought to be more similar morphologically to R. domesticus (group prolixus) than to members of the group pictipes and correspond to a poorly-preserved adult male therefore, currently it is difficult to validate its identity as a species [8,72]. Rhodnius brethesi differs from the remainder of the tribe by the size of the second antenna segment, which is longer than the third and the red or orange spots on the connexivum [41]. Finally, the pallescens group is composed of three morphologically very similar species. However, R. colombiensis was initially confused with R. prolixus of wild origin due to morphological similarities [56]. Rhodnius ecuadoriensis is characterized by its smaller size (Figure 4C). However, it has been proposed that this species should be grouped with R. pictipes due to the similarities of their antennal sensilla [56,85].

\subsection{Cytogenetic Studies}

In the Rhodniini tribe, the number of chromosomes is homogeneous in all of the 17 species analyzed so far (14 species of Rhodnius and three of Psammolestes), which were representative of the two genera and the three groups of the genus Rhodnius. Thus, the diploid chromosome number of the Rhodniini tribe is made up of 20 autosomes and the $X Y$ sex chromosomes; variations are observed between the Triatomini and Bolboderini tribes in the number of autosomes and sex chromosomes present in species and complexes [40,86-89]. Nucleolar persistence has also been observed during meiosis, as reflected by the presence of nucleoli or nucleolar corpuscles during the meiotic metaphase in 15 members of the tribe (P. tertius, R. brethesi, R. colombiensis, R. domesticus, R. ecuadoriensis, R. milesi, $R$. montenegrensis, $R$. nasutus, $R$. neglectus, $R$. neivai, $R$. pallescens, $R$. pictipes, $R$. prolixus, $R$. robustus, and $R$. stali) $[90,91]$. Flow cytometry measurements of genome size have been performed in four species of the tribe (R.ecuadoriensis, R. colombiensis, R. pallescens, and R. prolixus) and indicated sizes of $0.72,0.58$, 0.73 , and 0.75 picograms of haploid DNA, respectively, smaller than all other triatomines $[87,92,93]$.

Studies at the genus level in Psammolestes have shown that in all three species, heterochromatin and AT repeats are present in the Y chromosome. The chromocenter is formed by the sex chromosomes and autosomal heterochromatin is absent $[40,44,87]$. Studies of the genus Rhodnius have demonstrated the presence of autosomal heterochromatin in R. pallescens, R. colombiensis, R. domesticus, R. nasutus, R. taquarussuensis, and its absence in R. brethesi, R. ecuadoriensis, R. pictipes, R. neglectus, R. prolixus, $R$. robustus, and $R$. montenegrensis. In species that have constitutive heterochromatin, usually very tiny C-bands are observed $[40,87,89,92,94]$. However, in spite of the homogeneity of cytogenetic characteristics observed in the tribe, intra- and inter-specific differences exist in the chromosomal location of ribosomal genes. Two patterns of location have been observed: one on both sex chromosomes $\mathrm{X}$ and $\mathrm{Y}$ (P. tertius, R. domesticus, R. neglectus, R. neivai, R. milesi, R. pictipes, R. pallescens, and R. stali) and another only on the $\mathrm{X}$ chromosome ( $R$. nasutus, $R$. prolixus, $R$. robustus, $R$. colombiensis, and $R$. ecuadoriensis). In R. ecuadoriensis, both patterns were observed in populations from Peru and Ecuador. Analysis of ribosomal genes using cytogenetic techniques can be a useful marker of recent divergence of species or populations and allowed the formulation of two hypotheses regarding the evolution of ribosomal gene patterns, which may be due to: (i) loss of the loci in the $Y$ chromosome, with the XY pattern representing the ancestral state; or (ii) partial transfer of genes from the $\mathrm{X}$ to the $\mathrm{Y}$ chromosome through mechanisms of transposition or ectopic recombination between sex chromosomes [95,96].

There is clear utility in analyses of heterochromatin $C$ at the intraspecific level (e.g., for Triatoma infestans and Panstrongylus geniculatus) $[40,97,98]$. Cytogenetic analyses have been applied to different specimens of $R$. pallescens obtained from different geographical locations in Colombia and Panama, and revealed intraspecific variability: two cytotypes were described differing in terms of size, number and distribution of heterochromatin $\mathrm{C}$ during mitosis and meiosis. The frequencies of cytotypes varied in relation to the ecological and geographical characteristics of collection sites. Additionally, the cytotypes were consistent with morphological differences in size, morphometry of the wings and characters of the head [92,99]. Finally, cytogenetic characteristics (number and size of chromosomes, autosomal 
heterochromatin, and sex chromosomes) have also been used to evaluate intraspecific variability of different populations of R. prolixus and R. neglectus and no variation in cytotypes was observed with respect to the ecological and geographical characteristics of the populations analyzed [100].

\subsection{Isoenzymatic Studies}

Isoenzyme analyses have also been applied to species of the Rhodniini tribe, although few cross-sectional studies have examined all species at once. The first phylogenetic study addressing in several species of the Rhodniini tribe (R. brethesi, R. ecuadoriensis, R. nasutus, R. neglectus, R. pallescens, $R$. prolixus, $R$. pictipes, and $R$. stali) analyzed 12 enzymes, and the results of the analysis of distances and genetic variability allowed the grouping of species into the three groups currently known, in agreement with their geographical distribution [101]. Differently, one study proposed that Rhodnius species should be classified into only two groups: prolixus and pictipes, with the pictipes group including members of the group pallescens [80]. In addition, other isoenzymatic studies also showed that: (i) R. stali and $R$. pictipes despite their morphological similarities and geographical proximity are different species (ii) $R$. nasutus and R. neglectus are very closely related, indicating that their speciation probably occurred very recently, and that (ii) wild specimens erroneously identified as $R$. prolixus in Tolima (Colombia) were placed within the group pallescens and not with R. prolixus, and that they therefore could represent a new species that is known today as $R$. colombiensis [101,102]. Subsequently, two isoenzyme studies were published and included the species P. coreodes [103] and P. tertius [80] along with species of the three groups of the genus Rhodnius. In these studies, it was not possible to define the species status of Psamolestes in the tribe, because these species showed paraphyly with Rhodnius $[80,104]$. Another isoenzyme studies, addressing in species of the genus Rhodnius, showed that $R$. prolixus and $R$. robustus had identical electrophoretic patterns and were not reproductively isolated, however by using salivary, heme proteins was possible to differentiate these species $[40,80,104-106]$. The species status of $R$. neglectus was confirmed by genetic distance analysis and reproductive isolation although only one locus allowed its differentiation with $R$. nasutus $[104,106]$.

\subsection{Random Amplification of Polymorphic DNA (RAPD)}

With the advent of molecular techniques based on DNA, the use of high resolution markers, such as random amplification of polymorphic DNA (RAPD), became possible. This technique was used mainly for differentiating species of the tribe where morphological and isoenzyme differentiation was not possible (e.g., R. prolixus vs. R. robustus, R. ecuadoriensis vs. R. pictipes, and R. nasutus vs. R. neglectus). The electrophoretic patterns by RAPD allowed differentiation of all six species [107]. Additionally, RAPD was used to compare populations of domestic R. prolixus from Central America (Honduras) and South America (Colombia). RAPD electrophoretic patterns differed according to geographic location and showed that genetic variability was greater in specimens obtained from Colombia. Thus, it can be deduced that the Central American specimens were derived from those in South America; this conclusion was reached not only from the results of RAPD but also based on differences in morphology, because the specimens from Honduras were smaller. Finally, an isoenzymatic analysis showed no differences between the two types of specimens, suggesting a common origin [108]. However, RAPD studies also showed that R. prolixus (domestic) and R. colombiensis (wild) have different electrophoretic patterns, suggesting no genetic flow and that the effective migration rate between the species is insufficient to maintain genetic homogeneity in the two species [109]. RAPD has also been used to evaluate intraspecific genetic variability of populations of $P$. tertius of differing geographic origins in Brazil. One study found differences in electrophoretic patterns in association with geographic origin, and these results were supported by differences in isoenzyme patterns and morphological features [110]. 


\subsection{Microsatellites}

Microsatellite markers have also been used in the Rhodniini tribe, mainly with the aim of analyzing intraspecific variation given the high resolution of these markers. A scheme of 10 microsatellite loci was designed based on DNA sequences of R. prolixus and its amplification was tested in 10 species of the genus Rhodnius. Amplification of all loci was successful in R. robustus and in 6-9 of the species of the prolixus group, while in species of the groups pallescens and pictipes, amplification of more than three loci was not achieved [111]. Subsequent studies have used microsatellites to analyze intraspecific genetic structure in different populations of $R$. pallescens $[111,112], R$. nasutus [36], $R$. ecuadoriensis [113], and R. prolixus [22]. In populations of R. pallescens, field and laboratory specimens have been compared, and laboratory colonies of $R$. pallescens showed a different genetic structure than their wild relatives [112]. Studies of microsatellite markers in R. nasutus and R. ecuadoriensis showed that populations of these species from different geographic locations had genetic differences. For R. nasutus, four differentiated groups were revealed in eight geographic localities of the Brazilian Caatinga [36], and for R. ecuadoriensis, specimens in two biogeographically distinct localities of Ecuador had distinct genetic structures in association with other phenotypic differences [113]. Given its epidemiological importance, microsatellite markers were analyzed in wild and domestic populations of R. prolixus from Venezuela. No genetic differences were found, reflecting a high risk of wild populations easily invading human habitations [22].

\subsection{Sequencing of Mitochondrial and Nuclear Markers}

Improvements in sequencing technologies have enabled the analysis of mitochondrial and nuclear DNA markers. Analysis of these markers has been applied in several species of the tribe, both for intra- and inter-species analysis and together with other species of the Triatominae subfamily. Some of these studies have been carried out in combination with other molecular markers $[8,38]$. Nuclear and mitochondrial marker sequencing studies (26 conducted to date) have explored the phylogenetic relationships among the species of the tribe. Twelve studies explored species of the Rhodniini tribe and other tribes. The following mitochondrial markers have been evaluated: 16S rRNA (16S ribosomal RNA), 12S rRNA (12S ribosomal RNA), ND4 (4 subunit NADH dehydrogenase), Cytb (Cytochrome b), COI (Cytochrome oxidase I), and COII (Cytochrome Oxidase II). The following nuclear markers have been evaluated: $18 \mathrm{~S}$ (18S ribosomal RNA), ITS-2 (internal transcribed spacer of ribosomal DNA 2), EF-1 $\alpha$ (elongation factor 1 alpha), Wg (Wingless), and $28 \mathrm{~S}$ rRNA (RNA ribosomal 28S) [8,38,40]. The sequences of the Cytb gene were searched in Genbank using the following Entrez line: "esearch - $d b$ nucleotide -query "<organism $>$ CYTB"|efetch -format fasta" that yielded 226 records corresponding to 13 species of Rhodnius (Table S1) and Triatoma infestans sequence was used as outgroup. The alignment was made using MUSCLE, correct by hand and the sequence were translated to proteins in order to verify for stop codons in Mesquite 3.04. A maximum likelihood topology was obtained with the evolution model HKY + F + I + G4 (BIC score: 6711.067753) in IQ-TREE and node support was calculated with 1000 ultrafast bootstrap replicates. (Figure 5). In relation to the other tribes (mostly the Triatomini tribe), the Rhodniini tribe is of monophyletic origin [114-119]. In studies in which specimens of the Cavernicolini and Borbodelini tribes were included, these tribes were grouped with the Rhodniini and not with the Triatomini, although all tribes preserved their monophyletic status. However, it should be noted that some of these studies only included one or two species of the Rhodniini tribe, given that their focus was not on the Rhodniini tribe but on the subfamily Triatominae and other Reduviidae [120-125]. 


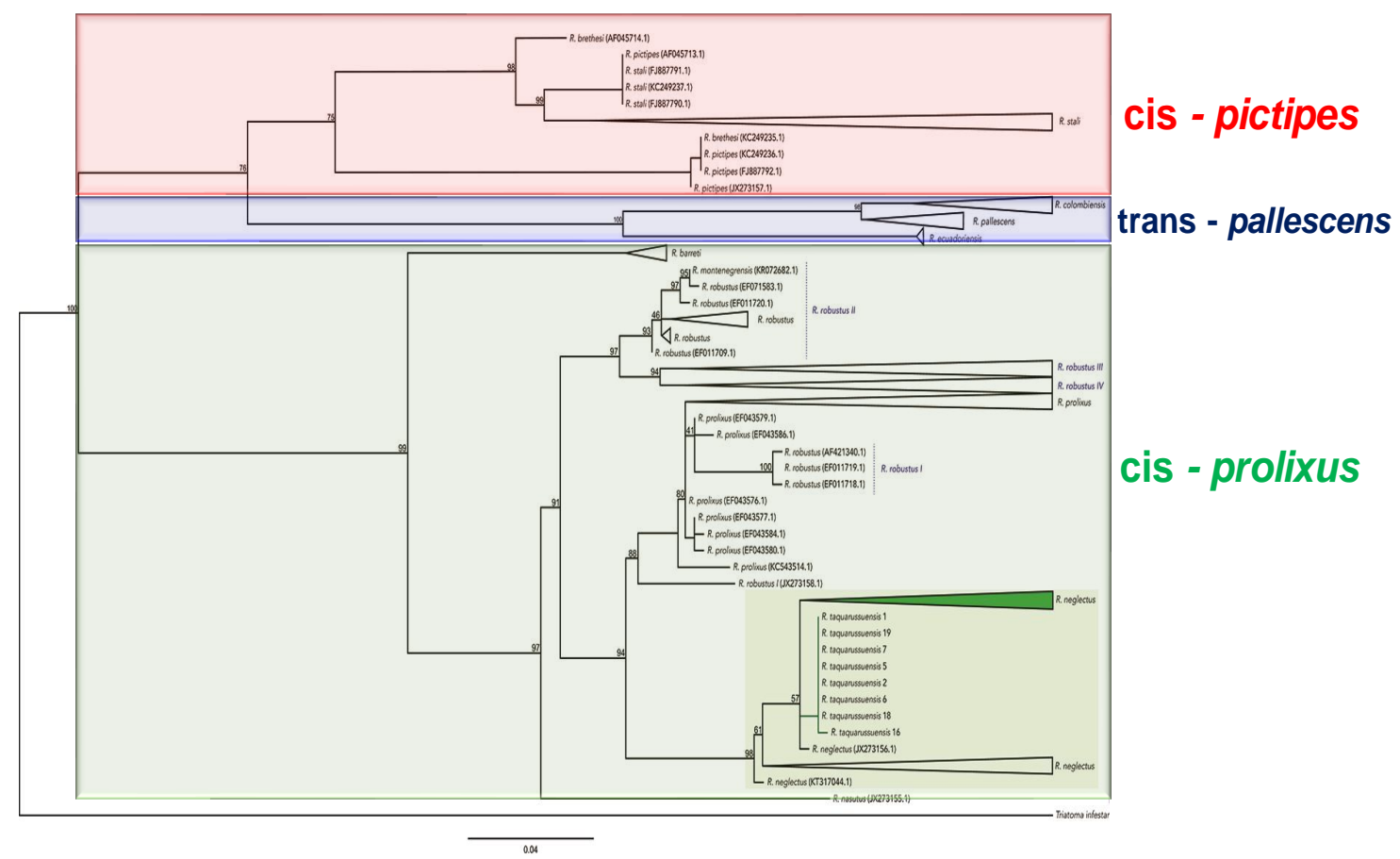

Figure 5. Maximum likelihood tree for Rhodnius based on Cytb sequences. The tree was reconstructed using sequences of Rhodnius species from GenBank.

The presence of two groupings within the pictipes group (Table 2) has led some authors to propose that the genus Rhodnius should be composed of clades or lineages. Some authors have proposed that the lineage prolixus be formed only by species of the group prolixus (named robustus lineage for other authors) and that another lineage should be formed by the species of the pallescens and pictipes groups called lineage pictipes $[7,79,80,126]$. Other authors proposed that the prolixus clade should be formed by species of the group prolixus and the group pictipes [122].

The remaining 14 studies focused on evaluating the phylogenetic relationships of Rhodniini species only and the grouping of species in particular. In these studies, the number of markers was limited to five: two mitochondrial (Cytb and ND4) and three nuclear (28S, AMPg, and ITS-2) [8]. Regarding phylogenetic relationships within the tribe, different issues have been identified that have been controversial with respect to previous studies: (i) paraphyly of the two genera of the tribe and grouping of the genus Psammolestes with members of the group prolixus were observed; (ii) the grouping of lineages within the genus Rhodnius was incongruent as well as the assignment of some species within groups; and (iii) the validity of some species was questionable due to inconsistencies in some phylogenies. These controversial aspects arose from the fact that many studies did not address all species of the tribe: most studies were intraspecific and used a limited number of markers. The objectives of most studies were limited to describing lineages but did not attempt the accurate delineation of all species nor the understanding the evolutionary processes that led to their formation $[8,38]$. 
Table 2. Characteristics of phylogenetic studies that have evaluated the relationships between groups of the genus Rhodnius.

\begin{tabular}{|c|c|c|c|c|c|}
\hline Grouping & $\begin{array}{l}\text { Nuclear } \\
\text { Marker }\end{array}$ & $\begin{array}{l}\text { Mitochondrial } \\
\text { Marker }\end{array}$ & Taxa & $\begin{array}{l}\text { Reconstruction } \\
\text { Method }\end{array}$ & Reference \\
\hline \multirow{8}{*}{$\begin{array}{l}\text { pictipes }+ \\
\text { pallescens }\end{array}$} & & $16 S$ & 4 & $\mathrm{MP}$ & Stothard et al., 1998 \\
\hline & & $16 \mathrm{~S}$, Cyt b & 8 & NJ & Lyman et al., 1999 \\
\hline & & 16S, Cyt b & 15 & & $\begin{array}{l}\text { Schofield and Dujardin, } \\
\qquad 1999 * \pm\end{array}$ \\
\hline & $28 \mathrm{~S}$ & $16 \mathrm{~S}$, Cyt b & 13 & $\mathrm{MP}, \mathrm{NJ}$ & Monteiro et al., 2000 \\
\hline & & Cyt b & 18 & $\mathrm{NJ}$ & Monteiro et al., $2018^{ \pm}$ \\
\hline & $28 \mathrm{~S}$ & Cyt b & 9 & $\mathrm{NJ}$ & Marquez et al., 2011 \\
\hline & & Cyt b & 12 & $\mathrm{MP}$ & Maia da Silva et al., 2007 \\
\hline & & Cyt b & 5 & ML, BI & Da Rosa et al., 2012 \\
\hline \multirow{5}{*}{$\begin{array}{l}\text { pictipes }+ \\
\text { prolixus }\end{array}$} & & $16 S, 12 S$ & 14 & $\mathrm{MP}, \mathrm{NJ}$ & Hypsa et al., 2002 \\
\hline & & $16 S$ & 14 & MP, ML & De Paula et al., $2007^{ \pm}$ \\
\hline & & $16 S$ & 14 & MP, ML & De Paula et al., 2005 \\
\hline & $18 S, 28 S$ & $\begin{array}{l}\text { 16S, Cyt b, COI, } \\
\text { COII }\end{array}$ & 10 & $\mathrm{ML}, \mathrm{BI}$ & Justi et al., 2014 \\
\hline & $18 \mathrm{~S}, 28 \mathrm{~S}, \mathrm{Wg}$ & $16 S$ & 11 & ML, BI & Justi et al., 2016 \\
\hline
\end{tabular}

\footnotetext{
${ }^{*}$ In this study, several markers were consolidated: RAPD, isoenzymes, morphometry and marker sequencing. NJ: Neighbor-Joining, MP: Maximum parsimony, ML: Maximum likelihood, BI: Bayesian inference. ${ }^{ \pm}$In this study, the sequences were collected from previous studies.
}

Several primarily morphological studies established that the Rhodniini tribe is made up of two monophyletic genera [41,46,56]. However, in nine studies both nuclear [ITS-2, 28S] and mitochondrial (Cyt b, 18S, 12S, and 16S) molecular markers have indicated the paraphyly of Psammolestes and Rhodnius $[38,79,114,115,117,118,122,123,127]$. Some studies showed that P. coreodes $[79,114,115,117$, 122,127], P. tertius $[79,114,115,117,122,127]$ and P. arthuri [123] were grouped with the species of the prolixus group of the genus Rhodnius, while a neighbor-joining analysis of Cytb sequences indicated the paraphyly of Psammolestes but not its grouping with the prolixus group [38,123].

Sequencing of molecular markers has detected groupings within the genus that have been postulated using other markers. However, sequencing did not confirm that the three groups were monophyletic nor the expected basal location of the pictipes group; these results have been controversial [40,117]. Some studies have found that the pictipes group is more closely related to the pallescens group $[38,56,79,118,119,126,128]$, while other studies described topologies in which the pictipes group is more closely associated with the prolixus group [117,121,122,127]. These differences in the associations between groups may be due to variability in study characteristics (Table 2): the number of taxa may be an important aspect that provides greater precision to phylogenetic reconstructions $[121,129]$.

Within the genus Rhodnius, there are also controversies regarding groupings of species. One example consists of the associations among species of the group pallescens, since after the identification of $R$. colombiensis it was grouped in some studies with R. ecuadoriensis $[79,122]$ and in others with $R$. pallescens $[38,117,127,130]$. The position of $R$. neivai within the group prolixus has also been questioned, because some studies have proposed that it should belong to the group pictipes [56] and others that it should belong to the prolixus group $[79,117,127]$. In other cases, a clear location was not identified in any of the groups $[38,80]$. The validity of the species $R$. robustus has been strongly questioned and for that reason phylogenetic studies have been carried out to explore its associations with $R$. prolixus, mainly due to the important epidemiological implications of confusing the two species due to their morphological similarity. Monteiro et al., 2000, conducted a first study using specimens 
of both species and sequenced 28S, 16S, and Cytb. These analyses showed discordances between morphological identification and phylogenetic grouping of individuals of both species [79].

These confusions in classification of these species led to a second study in which 26 different specimens of the two species from seven countries of Central and South America were used. Mitochondrial Cytb sequences were analyzed and the results showed that all specimens of $R$. prolixus - both from Central and South America-were grouped into a monophyletic and homogeneous cluster. By contrast, $R$. robustus showed a paraphyletic assembly composed of four clades (I-IV) from two different geographic regions: specimens of $R$. robustus clade I came from Venezuela and clades II, III, and IV came from French Guyana and different subregions of the Brazilian Amazon. Phylogenetic and distance analyses showed two main groups, one formed by R. prolixus and R. robustus $I$ and another formed by the three remaining clades of $R$. robustus. This drew attention to the genetic distance between $R$. robustus clade I and $R$. robustus clades II, III, and IV, and to the distance between $R$. robustus I and $R$. prolixus [61]. These groupings and the topology of the two species were replicated in a study that included 551 specimens from Orinoco and Amazonia [22]. Subsequently, R. robustus clade $\mathrm{V}$ was discovered in the central-north zone of the Amazon and grouped with $R$. robustus clade I and R. prolixus $[38,131]$. Subsequent studies used the term cryptic species for $R$. robustus instead of clades or genotypes I-IV and confirmed the paraphyly of this species with $R$. prolixus. In these studies, two techniques were used to differentiate the two species: band size of PCR amplicons derived from Cytb [62] or sequencing the nuclear marker AMPg (a region located in the fourth intron of transmembrane protein 165) [132]. Other arguments such as loss of fertility (number of eggs per female) in interspecific crosses favored the differentiation of the two species; however, no overall loss of fertility was observed (number of females that lay eggs) in these crosses [133,134].

Another study revealed that specimens similar to R. robustus (identified by classical morphometry) collected in Puerto Asis, Colombia, corresponded according to sequence analysis of Cytb and $28 \mathrm{~S}$ a new cryptic species of $R$. robustus, previously reported in Ecuador (Abad-Franch 2005,111). These specimens did not group with any other cryptic species of $R$. robustus and were located as a basal clade of the prolixus group [126]. However, more recent analyses of Cytb and morphometry indicated that the previously reported R. robustus is located as a basal clade only of $R$. robustus clade I and R. prolixus, and that these specimens do not correspond to $R$. robustus but rather represent a new species called $R$. barretti that is basal to the prolixus group $[38,63]$.

The analysis of Cytb and ITS-2 markers performed by Monteiro et al. has been applied in some species whose validity has been questioned. However, in some species the number of specimens analyzed was very limited. The first was $R$. amazonicus, which was questioned as a potential variant of R. pictipes; the study showed that this species had an independent origin and did not group with specimens of $R$. pictipes. Other species questioned by marker sequencing were R. milesi (because of its monophyly with specimens of R. neglectus) and R. montenegrensis (because of its location within $R$. robustus clade II). However, another study using Cytb sequences identified $R$. montenegrensis as an independent species of $R$. robustus, supported by morphological characters and PCR restriction fragment length polymorphism analysis of ITS-2 [135]. Several species have also been questioned due to a lack of information regarding molecular markers, including R. marabaensis, R. taquarusuensis, R. zeledoni, and R. dalessandroi. Sequencing of Cytb has also enabled identification of species such as R. stali in A. phalerata palms in Alto Beni, Bolivia, and R. prolixus in A. butyracea palms in Casanare, Colombia [38].

Finally, Cytb sequencing has also been used to assess intraspecific variability of several species of the tribe including R. prolixus. The results showed very low genetic diversity and that wild and domestic specimens shared 7/18 haplotypes found in all analyzed specimens [22]. In 157 specimens of R. nasutus collected in eight localities of the Brazilian Caatinga, 16 haplotypes of Cytb were detected, of which two major haplotypes were shared by specimens from five localities with low levels of diversity observed [36]. In the case of R. ecuadoriensis, 174 specimens from two provinces of Ecuador (Loja and Manabí) were analyzed and 34 haplotypes were identified, of which only three were shared between the 
two provinces. High haplotype diversity was observed and the model of isolation by distance applied to the two populations, showing that the populations of the two provinces were highly differentiated at the genetic level [113]. In R. pallescens, analysis of the Cytb, ND4 and 28S markers in populations from Panama and Colombia indicated the presence of two evolutionary lineages with genetic and morphological differences associated with their biogeographical and ecological distribution. It was even possible to observe genetic variation within lineages. In this manner, the Colombian lineage $R$. pallescens clade I could be subdivided into two populations, one from the north and one from southern Colombia and the Central American lineage R. pallescens clade II, which is composed of populations collected in western Colombia and different areas of Panama [92,130].

\subsection{The Advent of Genomic Data: Genomics and Transcriptomics in the Rhodninii}

Recently, additional sequencing tools have been applied to some members of the Triatominae subfamily and specifically to the Rhodniini tribe to obtain genome and transcriptome data. So far, the only member of the subfamily whose genome has been sequenced is $R$. prolixus; its genome was sequenced with $8 \times$ coverage using Sanger and 454 technologies and assembled using the CABOG program [120]. The genome was composed of 16,537 scaffolds with an N50 of $1.08 \mathrm{Mb}$, had an estimated size of $733 \mathrm{Mb}$ and achieved an assembly that was $95 \%$ complete, corresponding to 706 $\mathrm{Mb}$ without chromosome mapping. The most updated version (October 2017) includes annotation of 15,738 genes and 15,752 transcripts (Rpro version C3.3 in VectorBase) (https://www.vectorbase.org/ organisms/rhodnius-prolixus/cdc/rproc33).

This important approach to the genome of R. prolixus showed that $5.6 \%$ of the genome corresponded to transposable elements and demonstrated the presence of transcriptionally active genes transferred horizontally from Wolbachia. Exploration of the R. prolixus genome and knockdown experiments confirmed the presence of genes from different immune pathways (Toll and Imd) and the expansion of defensins, which function to control the intestinal microbiota but are unrelated to T. cruzi infection. Finally, comparative analysis of proteins revealed tandem expansions of genes families related to chemoreception, feeding, and digestion that potentially contributed to the evolution of a blood-feeding lifestyle [136].

The genome of $R$. prolixus has been used to search for satellite DNA sequences previously described in T. infestans using BLAST. The two species share four families of satellite DNA sequences of the 42 that are present in T. infestans, suggesting that their genomes are highly differentiated. Through hybridization experiments, it was demonstrated that these shared sequences were found at the autosomal level and the $\mathrm{X}$ chromosome in both species. By contrast, these sequences were absent in the $\mathrm{Y}$ chromosome in T. infestans and present in R. prolixus, suggesting a possible origin and evolution of the independent $Y$ chromosome [137].

Recently, mitochondrial genomes of three triatomine species (R. pictipes, Triatoma migrans, and Panstrongylus rufotuberculatus) were sequenced and compared with the mitochondrial genomes of Triatoma rubrofasciata, T. infestans, and Triatoma dimidiata to explore evolutionary relationships with the other Reduviidae species and between the Rhodniini and Triatomini tribes. The results showed that mitochondrial genes had different rates of molecular evolution and six genes (ND1, ND2, ND4L, ND5, ND6, and ATP8) had higher rates than other protein-coding genes (PCGs) in all species. R. pictipes showed differences in the start codons of three PCGs (ND4L, ND6, and ND1) and in the stop codons of two PCGs (ATP6 and ND1) compared with other Triatoma species. Additionally, the sister relationship between Stenopodainae and Triatominae subfamilies was strongly supported, and the Triatomini species formed a sister group to R. pictipes [138].

Several transcriptomes of $R$. prolixus have been analyzed. The first was derived from ovarian follicle tissue in order to explore the role of gene expression in insect reproductive processes. This study showed expression of some genes that promote oogenesis and development of the embryo, suggesting that they may be important in insect control processes [139]. The transcriptome of the digestive system has also been described, which enabled exploration and differentiation of transcripts present in the three 
segments of the intestine. The results showed that increased levels of some transcripts were related to the processes of digestion, detoxification, and transport of proteins through the digestive tract [140]. The transcriptome of the antennas has been described in all larval stages in order to characterize the expression of genes involved with the sensory functions of the insect. The results showed increased expression of genes related to chemoreceptors mainly in adult stages, as well as high expression of odorant binding proteins and chemosensory proteins in all stages [141]. Transcriptomes of T. dimidiata, T. infestans, and T. pallidipennis and the genome of R. prolixus have also been compared to evaluate the expression of gene families related to resistance to insecticides. In the case of $R$. prolixus, these studies revealed the expansion of two families, CYP4 (cytochrome P450-4) and CCE (carboxyl-Cholinesterases), related to pyrethroid resistance, odor processing, and degradation of hormones and pheromones [142].

A recent study analyzed and compared the transcriptomes of the head and salivary glands of $R$. robustus and $R$. montenegrensis; the validity of the latter species has been questioned due to its limited morphological differences compared with the former. The authors used RNA-Seq and detected 3055 single nucleotide polymorphisms (SNPs) distinguishing the two species and 216 transcripts with high levels of divergence. Several SNPs were detected in the same contig, suggesting that the two species were highly differentiated with possibly an extended time of divergence. In addition, the authors suggested that some of the genes studied could be subsequently tested for use in the identification and differentiation of these two species [143]. Finally, the most recent study combined the analysis of the previously reported transcriptomes of $R$. robustus and $R$. montenegrensis with the analysis of three molecular markers: Cytb, 28S, and ITS-2. In this study, it was concluded that $R$. montenegrensis and $R$. robustus clade II are in all likelihood the same species [127]. However, the repeatome and proteomic analyses detected high differentiation between R. prolixus, R. montenegrensis, and R. marabaensis, showing they are different species $[144,145]$.

\section{Biogeographical Hypotheses Pertaining to the Rhodninii Tribe}

Studies of biogeography in the Rhodniini tribe are limited in number but revealed high complexity, including theories of possible vicariance, duplications (sympatry), dispersion, and extinction events. These are related to several geological events such as: (i) the elevation of the Central Andes during the Miocene; (ii) the branching of the Andes into three separate mountain ranges (eastern, central, and western) during the Plio-Pleistocene; (iii) the formation of a land corridor connecting South and North America during the Pliocene; and (iv) the elevation of the Serra do Mar and the mountain systems of the Serra da Mantiqueira between the Oligocene and the Pleistocene [56,127]. Because morphometric, cytogenetic, and molecular markers have yielded contradictory results in several systematic and phylogenetic studies of the Rhodniini tribe, there are several contradictory hypotheses regarding the origin and diversification of the species within this tribe.

\subsection{Monophyletic Groups Hypothesis}

The first hypothesis was formulated by Schofield and Dujardin in 1999. It assumes that the ancestor of the Rhodniini was closest to R. pictipes species and originated during the Quaternary Period in arboreal habitats of the Amazon-Orinoco and tropical forests dispersed towards the south of the Brazilian Amazon and the northeast of Bolivia. In turn, the ancestor gave rise to $R$. stali in palms and invaded homes. This ancestor underwent other more specific dispersions, giving rise to the remaining species of the pictipes group: (i) towards the north of Colombia and central Venezuela, to R. neivai which is found in Copernicia tectorum palms; (ii) towards the border area between Brazil, Colombia and Venezuela, to R. brethesi which is found in palms of Leopoldinia piassaba; (iii) towards the Colombian Orinoquia, to $R$. dalessandroi which is morphologically very similar to $R$. brethesi but is found in other palms; and (iv) towards the state of Pará, Brazil, to R. paraenesis which is found in nests of Echymis crysurus (Figure 6A). The ancestor pictipes also gave rise to the group pallescens. In this case, the ancestor R. pictipes was dispersed towards the northwest of Colombia and through a bottleneck in the Sierra Nevada de Santa Marta and the northern tip of the Cordillera de los Andes, gave rise to R. pallescens, 
which is associated with Attalea butyracea palms and whose range extends to Central America and northwestern Colombia. The ancestor then dispersed through the Magdalena valley giving rise to $R$. colombiensis and into eastern Ecuador and Peru, giving rise to R. ecuadoriensis in Ecuador and northern Peru, possibly due to adaptation to the palm Phytolepas aequatorialis (Figure 6B) [56].

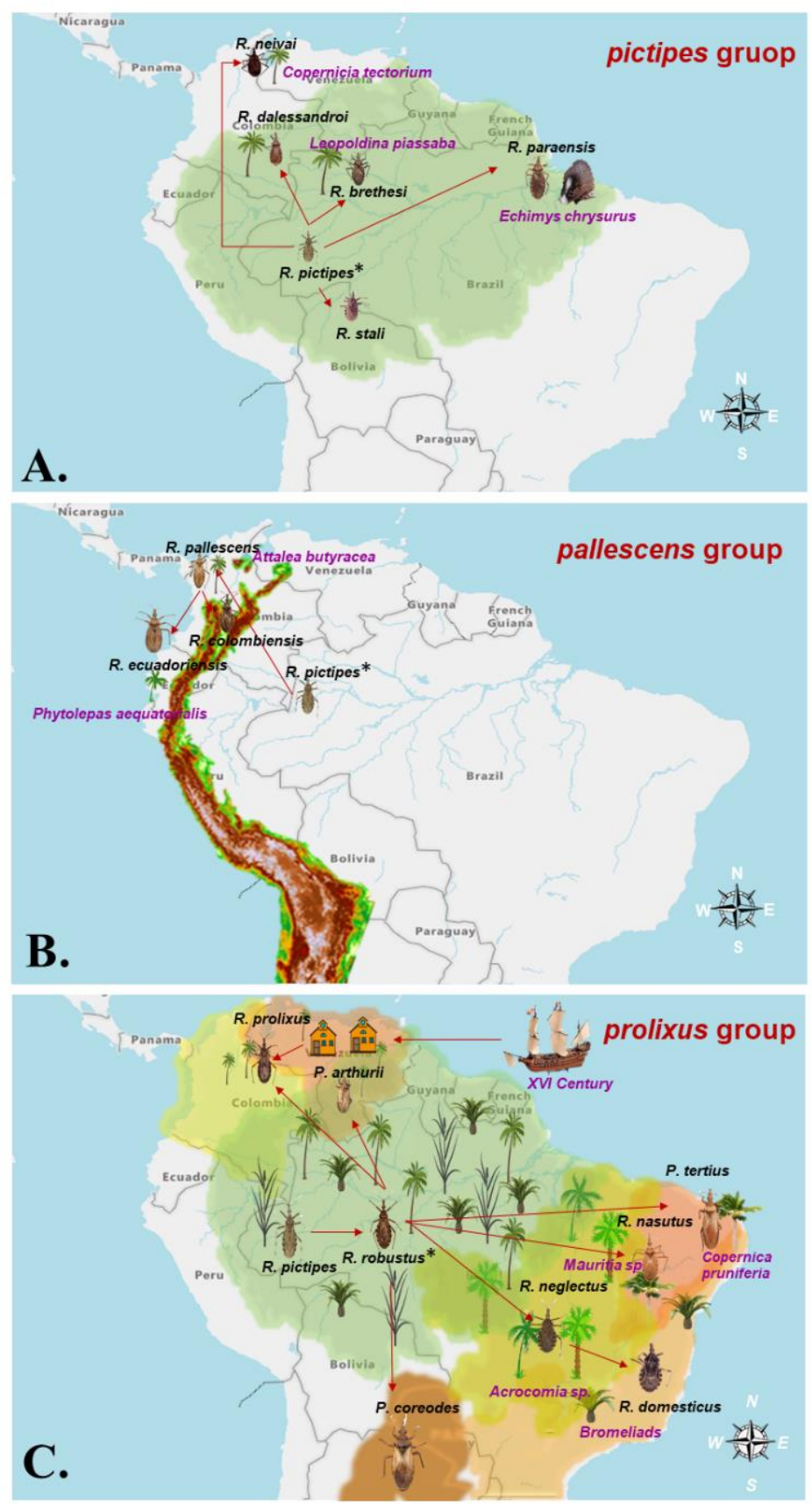

Figure 6. Monophyletic groups biogeographic hypothesis explaining speciation within the Rhodninii tribe. (A). Speciation and dispersion of pictipes group species (B). Speciation and dispersion of pallescens group species (C). Speciation and dispersion of prolixus group species. The asterisk $\left.{ }^{*}\right)$ indicates the species closest to the most recent common ancestor (MRCA) of Rhodniini tribe by each hypothesis.

The ancestor R. pictipes gave rise to R. robustus which was scattered throughout the Amazon in two forms: (i) a first form dispersed to the north reaching Venezuela where it gives rise to wild $R$. prolixus and P. arthuri; and (ii) a second form dispersed towards the south reaching the Brazilian Cerrado, where 
it gave rise to R. neglectus (associated with Mauritia and Acrocomia palms) and P. tertius. The latter and the southern form of $R$. robustus are dispersed towards the Caatinga where $R$. robustus gave rise to $R$. nasutus associated with the palm Copernicia prunifera. Additionally, R. neglectus is dispersed towards the Atlantic Forest where it gave rise to R. domesticus associated with Bromelia. Finally, this hypothesis proposes that the Spanish colonization of Venezuela triggered the domiciliation of wild $R$. prolixus and that the presence of R. prolixus domiciled in Central American countries may be due to the transport of some collections from Venezuela to El Salvador followed by their accidental release in rural homes. Subsequently, they dispersed and adapted to homes of several Central American countries. This last hypothesis is supported by morphometric analysis, isoenzyme analysis, and RAPD (Figure 6C) [56,108].

\subsection{Lineages Hypothesis}

Conflicting with these hypotheses, analysis of molecular markers did not support the idea that $R$. pictipes was the species closest to the ancestor of the three groups of Rhodnius. Instead, two topologies were generated, one in which $R$. pictipes was a sister group to the pallescens group and another in which it was a sister group to the prolixus group (Table 2). In addition, some studies grouped $R$. colombiensis as a sister species of $R$. pallescens and others as a sister speices of R. ecuadoriensis. Thus, two different hypotheses supported the two types of topologies and groupings observed $[7,122,127]$.

The second hypothesis, based on morphometric studies, mitochondrial markers and isoenzyme analysis, was proposed by Abad-Franch et al., 2009 and Díaz et al., 2016. Under this hypothesis, the genus Rhodnius is classified into two lineages (pictipes and robustus). The first gave rise to the transandean (pallescens) group and the Amazonian species (pictipes), while the second diversified into the Amazon (group robustus) and underwent radiation in nearby ecoregions (Orinoco, Chaco, Caatinga, Cerrado, and Mata Atlântica) allowing the formation of the cis-prolixus. Under this hypothesis it is assumed that $R$. colombiensis and R. pallescens are sister species. Thus, the ancestor of the pictipes lineage was dispersed to the northern part of the then low eastern mountain range of Colombia in the late Miocene (11-6 Ma) [7,131] or the mid-Miocene (16-11 Ma) [116]. Thus, the diversification of the pallescens and pictipes could be explained by a vicariance, either caused by the formation of the Pebas system [130] or by the elevation of the Andes mountain range during the Pliocene (5 Ma) [7,131]. Regarding the diversification of the ancestral pallescens, two hypotheses have been proposed: (i) the divergence of the ancestor of $R$. pallescens/R. colombiensis and R. ecuadoriensis could have occurred during the late Miocene, a period during which the Northern Andes had not reached more than half of its modern elevation (11-7 Ma), and the diversification of the ancestor of R. pallescens/R. colombiensis occurred with the elevation of the northern Andes and the separation of the R. pallescens lineages with the formation of the isthmus of Panama during the early Pliocene [130]; and (ii) diversification of the ancestral group pallescens occurred during the Pliocene with the elevation of the then-low eastern mountain range of Colombia, which divided the population into two main clades, a northern group comprising the ancestral forms of $R$. pallescens and R. colombiensis, and an isolated southern group which adapted to the new ecotopes and eventually gave rise to $R$. ecuadoriensis $[7,131]$. The radiation of the ancestor of pictipes in the Amazon is postulated to have occurred during the Pliocene and Pleistocene, according to the specific adaptations described under the first hypothesis, with the exception of $R$. neivai that was included in the robustus lineage [7].

However, the radiation of the taxa of the robustus lineage ( $R$. domesticus, $R$. neivai, $R$. robustus, and $R$. nasutus) in the ecoregions mentioned above can be attributed to another possible vicariance event at the end of the Miocene and subsequent radiation during the Pliocene. The division of the robustus-neglectus-prolixus group can be explained by more recent cladogenic events during the Pliocene and Pleistocene. Additionally, it was proposed that the lineages of $R$. robustus were potentially generated by parapatric speciation during the Pleistocene, and $R$. robustus in Venezuela does not appear to be a product of gene flow between R. prolixus and R. robustus from Amazon basin, but rather R. prolixus and $R$. robustus I seem to share a (relatively young) MRCA (most recent common ancestor) [7,61]. 


\subsection{Clades Hypothesis}

Finally, the third hypothesis proposed by Justi et al., 2016 using nuclear and mitochondrial markers proposes the formation of the prolixus clade (cis-andean) and locates the pictipes and prolixus groups as siblings, suggesting that the separation of the prolixus (cis-andean) group from the pictipes group (cis-andean) occurred by means of a vicariance during the formation of the Pebas system (23-11 Ma). Thus, the ancestor of the prolixus group was isolated in subregions of Brazil and that of the pictipes in the Chaco subregion and then the Amazon. Subsequently, the formation of the Acre system (10-7 Ma) allowed the ancestor of $R$. neivai/R. domesticus to diversify towards the north, giving rise to R. neivai, and towards the south, giving rise to $R$. domesticus. With respect to the group pallescens, this hypothesis proposes that divergence from the clade prolixus occurred during the late Miocene via the formation of the Pebas and that the separation of the three species occurred during the Pliocene. However unlike the second hypothesis, it proposes that separation occurred between $R$. pallescens and an ancestor $R$. colombiensis/R. ecuadoriensis, probably induced by the expansion of $R$. pallescens in Central America [122].

\section{Future Perspectives}

In the Andean countries, the main triatomines responsible for vector-mediated transmission of T. cruzi to people are those of the genus Rhodnius; thus, control measures are directed to species of this genus. Therefore, further studies of the evolution, phylogeny, biogeography, ecology, physiology, and behavior of Rhodnius species are needed to help improve existing Chagas disease control programs [8, $10,38]$. One of the primary steps in any control program is the accurate identification of vector species and detailed understanding of their genetic and population structures.

Therefore, future studies should be based on integrative taxonomy approaches, taking into account the delimitations of species, the synthesis of morphological characteristics with information obtained from molecular genetic studies, biogeography, phylogeography, behavior, ecology, and development [146]. The incongruities shown so far between morphological and genetic studies are due to several intrinsic limitations of several techniques. Studies to date have focused on describing groupings of species within the tribe but have not delimited these groups within the tribe, which has generated systematic problems.

One of the most important limitations of current studies lies in the limited morphological variability between different species of the tribe; therefore, there are few synapomorphic characters. Added to this, identification of some species of the tribe (R. prolixus vs. R. robustus) relies on few characters with complex interpretation, resulting in inconsistent results between morphological studies and errors in morphological identification. These problems arose because few cladistic studies or studies based on morphological characters of all species of the Rhodniini tribe have been conducted $[8,74,147]$.

Some characters used for identification of species are affected by phenotypic variability and morphological plasticity in association with environmental changes. The latter generates minor morphological changes between populations of the same species and can therefore lead to erroneous identification, such as the presence of color morphotypes in $R$. nasutus. These changes can occur before genetic barriers are present between species and therefore will generate inconsistencies between morphological and genetic studies. Phenotypic variability and morphological plasticity can also lead to morphological convergence between species that are genetically distinct but are adapted to the same ecological niche, as is the case for species of the prolixus group $[38,40]$. Due to these complicating factors, future studies should focus on identifying morphological synapomorphic characters that facilitate differentiation and identification of appropriate species, and are complemented by genetic, biogeographic, behavioral, and ecological analyses. This would help in laying out a rational approach to the systematics of the tribe.

Complexities in delineation of species of the Rhodniini tribe could also be addressed through crosses in the laboratory: these would allow evaluation of reproductive isolation and the potential presence of hybrids between species. Although several studies have been carried out in the Triatomini tribe, few reports have documented a cross between members of the Rhodniini tribe (R. prolixus $-R$. 
robustus and R. prolixus-R. nasutus) $[134,148]$. This reflects the complex morphological identification of species of the tribe and the difficulties associated with identification of hybrids, because these usually correspond to morphological intermediates between the parental species. Thus, it is important that future studies carry out interspecific crosses to verify if members of the tribe meet the biological definition of species. These crosses should be evaluated not only at the level of morphological characters, but also using genetic characters such as molecular markers. Analyses of nuclear DNA and mitochondrial DNA can both be used for appropriate identification of species involved in crosses as well as for analysis of the progeny of crosses: the nuclear and mitochondrial DNA sequences allow identification of introgression and the latter allows identification of hybridization processes [149].

Finally, genetic studies in the tribe have been limited, and the majority of them have focused on studying relationships between the Rhodniini tribe and other members of the Triatominae or Reduviidae. Additionally, studies that have exclusively examined species of the tribe have focused on analysis of epidemiologically important species or been focused at the intra-specific level. In addition, different studies have examined different species and are thus not directly comparable. There is only one study in which Cytb sequences from most of the tribe's species were included [38]. Therefore, it is necessary to carry out studies that include a large number of species of the Rhodniini tribe to attempt relevant delineation of tribe members.

In Anopheles and several species of the Triatomini tribe, nuclear ribosomal sequences present intragenomic variability due to their high copy number. Thus, data obtained from these specimens should be analyzed with caution because errors of interpretation may occur. Multilocus approaches will enable better resolution in phylogenetic analyses and also allow identification of introgression and potential hybridization events. Therefore, attempts to design molecular markers for multilocus studies are required; these markers need to be sequenced in a representative number of species to elucidate their phylogenetic relationships and to provide useful tools for integrative taxonomy [149].

Finally, genomic and transcriptomic resources in the tribe are scarce. To date, only the mutation rates of Cytb sequences in species of the genus Triatoma and of mitochondrial loci in R. pictipes have been examined. This information may be used for coalescence analyses and phylogeographic reconstructions in future studies. However, the genomic mutation rate of at least one representative species of the Rhodniini tribe remains to be determined. The genome of $R$. prolixus has low coverage and has not yet been assembled at a chromosomal level. Therefore, future studies could improve genomic resources, especially because the resolution of phylogenies drastically improves when genomic data are used, as previously documented in plants and in a recent phylogenomic analysis of the Hemiptera $[150,151]$.

\section{Conclusions}

In spite of the valuable contributions of studies carried out to date on species of the Rhodniini tribe, limitations in our understanding have led to inconsistencies between and within morphological and phylogenetic studies. In turn, this has created three problems in the systematics of the Rhodniini tribe: (i) paraphyly of two genera in the tribe, (ii) different types of classification and grouping of the species of the genus Rhodnius, and (iii) difficulties in identification and adequate delineation of some species. These issues have resulted in generations of conflicting hypotheses regarding the origin, evolution, and dispersion of the species of the Rhodniini tribe. This information is of great importance because of the biologic role of several species of the tribe in transmission of T. cruzi. Thus, it is necessary to conduct further genetic, ecological, morphological, and biogeographical studies of the tribe to provide an integrative approach that can address the current systematic and taxonomic inconsistencies; in turn, these studies will provide the information necessary to develop improved vector control strategies for Chagas disease.

Supplementary Materials: The following are available online at http://www.mdpi.com/1424-2818/12/3/97/s1, Table S1: Table S1_Cytb_Rhodnius_Sequences. 
Author Contributions: “Conceptualization, C.H. and J.D.R.; writing-original draft preparation, C.H. and J.D.R; writing-review and editing, J.A.d.R., G.A.V. and F.G.; funding acquisition, C.H. and J.D.R. All authors have read and agreed to the published version of the manuscript."

Funding: This work was funded by DIRECCION DE INVESTIGACION E INNOVACION from UNIVERSIDAD DEL ROSARIO "Big grant: Genómica, evolución y biogeografía de especies del género Rhodnius: vectores de la enfermedad de Chagas-IV-FGD002". CH is funded by the Colombian Science, Technology, and Innovation Department (Colciencias) call for PhD training in Colombia, within the framework of the National Programme for Promoting Research Training (sponsorship call 727).

Acknowledgments: Carolina Hernández wants to dedicate this review to the memory of her father LUVIN HERNANDEZ VANEGAS whom died on June 6th, 2018 and his great legacy: His eternal love and the principles of honesty, responsibility and dignity. Thanks, Dad, for all you gave me. I am going to love and remember you forever. We thank Edanz Group (www.edanzediting.com/ac) for editing a draft of this manuscript. We thank Juliana Damieli Nascimento for taking images of insects used in Figures 3 and 4 and we thank Fabian Salgado for reconstructing the ML tree in Figure 5.

Conflicts of Interest: The authors declare that the research was conducted in the absence of any commercial or financial relationships that could be construed as a potential conflict of interest.

\section{References}

1. Lidani, K.C.F.; Andrade, F.A.; Bavia, L.; Damasceno, F.S.; Beltrame, M.H.; Messias-Reason, I.J.; Sandri, T.L. Chagas Disease: From Discovery to a Worldwide Health Problem. Front. Public Health 2019, 7, 166. [CrossRef]

2. WHO. Chagas disease in Latin America: An epidemiological update based on 2010 estimates. Wkly. Epidemiol. Rec. 2015, 90, 33-43.

3. Waleckx, E.; Gourbière, S.; Dumonteil, E. Intrusive versus domiciliated triatomines and the challenge of adapting vector control practices against Chagas disease. Mem. Inst. Oswaldo Cruz 2015, 110, 324-338. [CrossRef] [PubMed]

4. Bern, C. Chagas' Disease. N. Engl. J. Med. 2015, 373, 456-466. [CrossRef] [PubMed]

5. De Noya, B.A.; González, O.N. An ecological overview on the factors that drives to Trypanosoma cruzi oral transmission. Acta Trop. 2015, 151, 94-102. [CrossRef]

6. Flores-Ferrer, A.; Marcou, O.; Waleckx, E.; Dumonteil, E.; Gourbière, S. Evolutionary ecology of Chagas disease; what do we know and what do we need? Evol. Appl. 2018, 11, 470-487. [CrossRef]

7. Abad-Franch, F.; Monteiro, F.A.; Jaramillo-O., N.; Gurgel-Gonçalves, R.; Dias, F.B.S.; Diotaiuti, L. Ecology, evolution, and the long-term surveillance of vector-borne Chagas disease: A multi-scale appraisal of the tribe Rhodniini (Triatominae). Acta Trop. 2009, 110, 159-177. [CrossRef]

8. Justi, S.A.; Galvão, C. The Evolutionary Origin of Diversity in Chagas Disease Vectors. Trends Parasitol. 2017, 33, 42-52. [CrossRef]

9. Poinar, G. A primitive triatomine bug, Paleotriatoma metaxytaxa gen. et sp. nov. (Hemiptera: Reduviidae: Triatominae), in mid-Cretaceous amber from northern Myanmar. Cretac. Res. 2019, 93, 90-97. [CrossRef]

10. Gorla, D.; Noireau, F. Geographic Distribution of Triatominae Vectors in America. In American Trypanosomiasis Chagas Disease; Elsevier: Amsterdam, The Netherlands, 2017; pp. 197-221. ISBN 978-0-12-801029-7.

11. Da Rosa, J.A.; Souza, E.S.; da Costa Teixeira, A.; Barbosa, R.R.; de Souza, A.J.; Belintani, T.; Nascimento, J.D.; Gil-Santana, H.R.; de Oliveira, J. Third record of Rhodnius amazonicus and comparative study with R. pictipes (Hemiptera, Reduviidae, Triatominae). Acta Trop. 2017, 176, 364-372. [CrossRef]

12. Schofield, C.J.; Galvão, C. Classification, evolution, and species groups within the Triatominae. Acta Trop. 2009, 110, 88-100. [CrossRef] [PubMed]

13. Bilheiro, A.B.; da Rosa, J.A.; de Oliveira, J.; Belintani, T.; Fontes, G.; Medeiros, J.F.; de Meneguetti, D.U.O.; Camargo, L.M.A. First Report of Natural Infection with Trypanosoma cruzi in Rhodnius montenegrensis (Hemiptera, Reduviidae, Triatominae) in Western Amazon, Brazil. Vector Borne Zoonotic Dis. 2018, 18, 605-610. [CrossRef] [PubMed]

14. Guhl, F.; Vallejo, G.A. Trypanosoma (Herpetosoma) rangeli Tejera, 1920: An updated review. Memórias do Instituto Oswaldo Cruz 2003, 98, 435-442. [CrossRef] [PubMed]

15. Ocaña-Mayorga, S.; Aguirre-Villacis, F.; Pinto, C.M.; Vallejo, G.A.; Grijalva, M.J. Prevalence, Genetic Characterization, and 18S Small Subunit Ribosomal RNA Diversity of Trypanosoma rangeli in Triatomine and Mammal Hosts in Endemic Areas for Chagas Disease in Ecuador. Vector-Borne Zoonotic Dis. 2015, 15, 732-742. [CrossRef] [PubMed] 
16. Salazar-Antón, F.; Urrea, D.A.; Guhl, F.; Arévalo, C.; Azofeifa, G.; Urbina, A.; Blandón-Naranjo, M.; Sousa, O.E.; Zeledón, R.; Vallejo, G.A. Trypanosoma rangeli genotypes association with Rhodnius prolixus and R. pallescens allopatric distribution in Central America. Infect. Genet. Evol. 2009, 9, 1306-1310. [CrossRef]

17. Saldaña, A.; Santamaría, A.M.; Pineda, V.; Vásquez, V.; Gottdenker, N.L.; Calzada, J.E. A darker chromatic variation of Rhodnius pallescens infected by specific genetic groups of Trypanosoma rangeli and Trypanosoma cruzi from Panama. Parasit. Vectors 2018, 11, 423. [CrossRef]

18. Urrea, D.A.; Carranza, J.C.; Cuba, C.A.C.; Gurgel-Gonçalves, R.; Guhl, F.; Schofield, C.J.; Triana, O.; Vallejo, G.A. Molecular characterisation of Trypanosoma rangeli strains isolated from Rhodnius ecuadoriensis in Peru, R. colombiensis in Colombia and R. pallescens in Panama, supports a co-evolutionary association between parasites and vectors. Infect. Genet. Evol. 2005, 5, 123-129. [CrossRef]

19. Urrea, D.A.; Guhl, F.; Herrera, C.P.; Falla, A.; Carranza, J.C.; Cuba-Cuba, C.; Triana-Chávez, O.; Grisard, E.C.; Vallejo, G.A. Sequence analysis of the spliced-leader intergenic region (SL-IR) and random amplified polymorphic DNA (RAPD) of Trypanosoma rangeli strains isolated from Rhodnius ecuadoriensis, $R$. colombiensis, R. pallescens and R. prolixus suggests a degree of co-evolution between parasites and vectors. Acta Trop. 2011, 120, 59-66.

20. Vallejo, G.A.; Guhl, F.; Schaub, G.A. Triatominae-Trypanosoma cruzi/T. rangeli: Vector-parasite interactions. Acta Trop. 2009, 110, 137-147. [CrossRef]

21. Angulo, V.M.; Esteban, L.; Luna, K.P. Attalea butyracea próximas a las viviendas como posible fuente de infestación domiciliaria por Rhodnius prolixus (Hemiptera: Reduviidae) en los Llanos Orientales de Colombia. Biomedica 2012, 32, 277-285. [CrossRef]

22. Fitzpatrick, S.; Feliciangeli, M.D.; Sanchez-Martin, M.J.; Monteiro, F.A.; Miles, M.A. Molecular Genetics Reveal That Silvatic Rhodnius prolixus Do Colonise Rural Houses. PLoS Negl. Trop. Dis. 2008, 2, e210. [CrossRef] [PubMed]

23. Fitzpatrick, S.; Watts, P.C.; Feliciangeli, M.D.; Miles, M.A.; Kemp, S.J. A panel of ten microsatellite loci for the Chagas disease vector Rhodnius prolixus (Hemiptera: Reduviidae). Infect. Genet. Evol. 2009, 9, $206-209$. [CrossRef]

24. Hernández, C.; Salazar, C.; Brochero, H.; Teherán, A.; Buitrago, L.S.; Vera, M.; Soto, H.; Florez-Rivadeneira, Z.; Ardila, S.; Parra-Henao, G.; et al. Untangling the transmission dynamics of primary and secondary vectors of Trypanosoma cruzi in Colombia: Parasite infection, feeding sources and discrete typing units. Parasit. Vectors 2016, 9, 620. [CrossRef] [PubMed]

25. Mejía-Jaramillo, A.; Agudelo-Uribe, L.; Dib, J.; Ortiz, S.; Solari, A.; Triana-Chávez, O. Genotyping of Trypanosoma cruzi in a hyper-endemic area of Colombia reveals an overlap among domestic and sylvatic cycles of Chagas disease. Parasit. Vectors 2014, 7, 108. [CrossRef] [PubMed]

26. Monroy, C.; Rodas, A.; Mejía, M.; Rosales, R.; Tabaru, Y. Epidemiology of Chagas disease in Guatemala: Infection rate of Triatoma dimidiata, Triatoma nitida and Rhodnius prolixus (Hemiptera, Reduviidae) with Trypanosoma cruzi and Trypanosoma rangeli (Kinetoplastida, Trypanosomatidae). Mem. Inst. Oswaldo Cruz 2003, 98, 305-310. [CrossRef] [PubMed]

27. Cuba Cuba, C.A.; Abad-Franch, F.; Roldán Rodríguez, J.; Vargas Vásquez, F.; Pollack Velásquez, L.; Miles, M.A. The Triatomines of Northern Peru, with Emphasis on the Ecology and Infection by Trypanosomes of Rhodnius ecuadoriensis (Triatominae). Mem. Inst. Oswaldo Cruz 2002, 97, 175-183. [CrossRef]

28. Grijalva, M.J.; Villacís, A.G.; Moncayo, A.L.; Ocaña-Mayorga, S.; Yumiseva, C.A.; Baus, E.G. Distribution of triatomine species in domestic and peridomestic environments in central coastal Ecuador. PLoS Negl. Trop. Dis. 2017, 11, e0005970. [CrossRef]

29. Calzada, J.E.; Pineda, V.; Montalvo, E.; Alvarez, D.; Santamaría, A.M.; Samudio, F.; Bayard, V.; Cáceres, L.; Saldaña, A. Human trypanosome infection and the presence of intradomicile Rhodnius pallescens in the western border of the Panama Canal, Panama. Am. J. Trop. Med. Hyg. 2006, 74, 762-765. [CrossRef]

30. Gottdenker, N.L.; Chaves, L.F.; Calzada, J.E.; Saldaña, A.; Carroll, C.R. Host Life History Strategy, Species Diversity, and Habitat Influence Trypanosoma cruzi Vector Infection in Changing Landscapes. PLoS Negl. Trop. Dis. 2012, 6, e1884. [CrossRef]

31. Pineda, V.; Montalvo, E.; Alvarez, D.; Santamaría, A.M.; Calzada, J.E.; Saldaña, A. Feeding sources and trypanosome infection index of Rhodnius pallescens in a Chagas disease endemic area of Amador County, Panama. Rev. Inst. Med. Trop. Sao Paulo 2008, 50, 113-116. [CrossRef] 
32. de Vasquez, A.M.; Samudio, F.E.; Saldaña, A.; Paz, H.M.; Calzada, J.E. Eco-epidemiological aspects of Trypanosoma cruzi, Trypanosoma rangeli and their vector (Rhodnius pallescens) in Panama. Rev. Inst. Med. Trop. Sao Paulo 2004, 46, 217-222. [CrossRef] [PubMed]

33. Zeledón, R.; Marín, F.; Calvo, N.; Lugo, E.; Valle, S. Distribution and ecological aspects of Rhodnius pallescens in Costa Rica and Nicaragua and their epidemiological implications. Mem. Inst. Oswaldo Cruz 2006, 101, 75-79. [CrossRef] [PubMed]

34. Justi, S.A.; Noireau, F.; Cortez, M.R.; Monteiro, F.A. Infestation of peridomestic Attalea phalerata palms by Rhodnius stali, a vector of Trypanosoma cruzi in the Alto Beni, Bolivia: Infestation of peridomestic palms by a vector of Trypanosoma cruzi in Bolivia. Trop. Med. Int. Health 2010, 15, 727-732. [CrossRef] [PubMed]

35. Gurgel-Gonçalves, R.; Galvão, C.; Costa, J.; Peterson, A.T. Geographic Distribution of Chagas Disease Vectors in Brazil Based on Ecological Niche Modeling. J. Trop. Med. 2012, 2012, 1-15. [CrossRef]

36. Peretolchina, T.; Pavan, M.G.; Corrêa-Antônio, J.; Gurgel-Gonçalves, R.; Lima, M.M.; Monteiro, F.A. Phylogeography and demographic history of the Chagas disease vector Rhodnius nasutus (Hemiptera: Reduviidae) in the Brazilian Caatinga biome. PLoS Negl. Trop. Dis. 2018, 12, e0006731. [CrossRef]

37. Ramos, L.J.; de Castro, G.V.S.; de Souza, J.L.; de Oliveira, J.; da Rosa, J.A.; Camargo, L.M.A.; da Cunha, R.M.; de Meneguetti, D.U.O. First report of Rhodnius neglectus (Hemiptera, Reduviidae, Triatominae) from the State of Acre, Brazil, and the Brazilian Western Amazon Region. Rev. Soc. Bras. Med. Trop. 2018, 51, 212-214. [CrossRef]

38. Monteiro, F.A.; Weirauch, C.; Felix, M.; Lazoski, C.; Abad-Franch, F. Evolution, Systematics, and Biogeography of the Triatominae, Vectors of Chagas Disease. Adv. Parasitol. 2018, 99, 265-344.

39. Carcavallo, R. Aspects of the epidemiology of Chagas disease in Venezuela and Argentina. American Trypanosomiasis Research. PAHO Sci. Publ. 1976, 318, 347-358.

40. Dujardin, J.; Schofield, C.; Panzera, F. Les vecteurs de la maladie de Chagas. Brussels: Académie Royale des Sciences; Académie Royale des Sciences d'Outre-Mer: Brussels, Belgium, 2002; ISBN 90-75652-27-5.

41. Lent, H.; Wygodzinsky, P. Revision of the Triatominae [Hemiptera, Reduviidae], and their significance as vectors of Chagas' disease. Bull. Am. Mus. Nat. Hist. 1979, 163, 123-520.

42. Ceccarelli, S.; Balsalobre, A.; Medone, P.; Cano, M.E.; Gurgel Gonçalves, R.; Feliciangeli, D.; Vezzani, D.; Wisnivesky-Colli, C.; Gorla, D.E.; Marti, G.A.; et al. DataTri, a database of American triatomine species occurrence. Sci. Data 2018, 5, 180071. [CrossRef]

43. Abad-Franch, F.; Lima, M.M.; Sarquis, O.; Gurgel-Gonçalves, R.; Sánchez-Martín, M.; Calzada, J.; Saldaña, A.; Monteiro, F.A.; Palomeque, F.S.; Santos, W.S.; et al. On palms, bugs, and Chagas disease in the Americas. Acta Trop. 2015, 151, 126-141. [CrossRef] [PubMed]

44. Oliveira, J.; Alevi, K.C.C.; Fonseca, E.O.L.; Souza, O.M.F.; Santos, C.G.S.; Azeredo-Oliveira, M.T.V.; da Rosa, J.A. New record and cytogenetic analysis of Psammolestes tertius Lent \& Jurberg, 1965 (Hemiptera, Reduviidae, Triatominae) from Bahia State, Brazil. Genet. Mol. Res. 2016, 15, 1-6.

45. Velásquez-Ortiz, N.; Hernández, C.; Herrera, G.; Cruz-Saavedra, L.; Higuera, A.; Arias-Giraldo, L.M.; Urbano, P.; Cuervo, A.; Teherán, A.; Ramírez, J.D. Trypanosoma cruzi infection, discrete typing units and feeding sources among Psammolestes arthuri (Reduviidae: Triatominae) collected in eastern Colombia. Parasit. Vectors 2019, 12, 157. [CrossRef] [PubMed]

46. Galvão, C.; Carcavallo, R.; Rocha, D.D.S.; Jurberg, J. A checklist of the current valid species of the subfamily Triatominae Jeannel, 1919 (Hemiptera, Reduviidae) and their geographical distribution, with nomenclatural and taxonomic notes. Zootaxa 2003, 202, 1. [CrossRef]

47. Abad-Franch, F.; Palomeque, F.S.; Aguilar, H.M.; Miles, M.A. Field ecology of sylvatic Rhodnius populations (Heteroptera, Triatominae): Risk factors for palm tree infestation in western Ecuador: Rhodnius and palm trees in Ecuador. Trop. Med. Int. Health 2005, 10, 1258-1266. [CrossRef]

48. Arboleda, S.; Gorla, D.E.; Porcasi, X.; Saldaña, A.; Calzada, J.; Jaramillo-O., N. Development of a geographical distribution model of Rhodnius pallescens Barber, 1932 using environmental data recorded by remote sensing. Infect. Genet. Evol. 2009, 9, 441-448. [CrossRef]

49. Abad-Franch, F.; Paucar, A.; Carpio, C.; Cuba, C.A.; Aguilar, H.M.; Miles, M.A. Biogeography of Triatominae (Hemiptera: Reduviidae) in Ecuador: Implications for the design of control strategies. Mem. Inst. Oswaldo Cruz 2001, 96, 611-620. [CrossRef] 
50. Arévalo, A.; Carranza, J.C.; Guhl, F.; Clavijo, J.A.; Vallejo, G.A. Comparación del ciclo de vida de Rhodnius colombiensis Moreno, Jurberg \& Galvão, 1999 y Rhodnius prolixus Stal, 1872(Hemiptera, Reduviidae, Triatominae) en condiciones de laboratorio. Biomedica 2007, 27, 119.

51. Moreno Mejia, J.; Galvao, C.; Jurberg, J. Rhodnius colombiensis sp N. da Colombia com quadros comparativos entre estruturas fálicas do gênero Rhodnius Stal, 1859. Entomologia y Vectores 1999, 6, 601-617.

52. Guhl, F.; Aguilera, G.; Pinto, N.; Vergara, D. Actualización de la distribución geográfica y ecoepidemiología de la fauna de triatominos (Reduviidae: Triatominae) en Colombia. Biomedica 2007, 27, 143. [CrossRef]

53. Cedillos, R.A.; Romero, J.E.; Sasagawa, E. Elimination of Rhodnius prolixus in El Salvador, Central America. Mem. Inst. Oswaldo Cruz 2012, 107, 1068-1069. [CrossRef] [PubMed]

54. Hashimoto, K.; Schofield, C.J. Elimination of Rhodnius prolixus in Central America. Parasites Vectors 2012, 5, 45. [CrossRef] [PubMed]

55. Nakagawa, J.; Juárez, J.; Nakatsuji, K.; Akiyama, T.; Hernandez, G.; Macal, R.; Flores, C.; Ortiz, M.; Marroquín, L.; Bamba, T.; et al. Geographical characterization of the triatomine infestations in north-central Guatemala. Ann. Trop. Med. Parasitol. 2005, 99, 307-315. [CrossRef] [PubMed]

56. Schofield, C.; Dujardin, J.-P. Theories on the Evolution of Rhodnius. Actu. Biol. 1999, 21, 183-197.

57. Antonio-Campos, A.; Nicolás-Cruz, A.; Girón-Arias, J.I.; Rivas, N.; Alejandre-Aguilar, R. Presence of Rhodnius prolixus Stäl, 1859 (Hemiptera: Reduviidae) in Oaxaca, Mexico, ten years after the certification of its elimination. J. Vector Ecol. 2019, 44, 293-295. [CrossRef]

58. Bérenger, J.-M.; Pluot-Sigwalt, D.; Pagès, F.; Blanchet, D.; Aznar, C. The triatominae species of French Guiana (Heteroptera: Reduviidae). Mem. Inst. Oswaldo Cruz 2009, 104, 1111-1116. [CrossRef]

59. Gurgel-Gonçalves, R.; Abad-Franch, F.; Ferreira, J.B.C.; Santana, D.B.; Cuba, C.A.C. Is Rhodnius prolixus (Triatominae) invading houses in central Brazil? Acta Trop. 2008, 107, 90-98. [CrossRef]

60. Hiwat, H. Triatominae species of Suriname (Heteroptera: Reduviidae) and their role as vectors of Chagas disease. Mem. Inst. Oswaldo Cruz 2014, 109, 452-458. [CrossRef]

61. Monteiro, F.A.; Barrett, T.V.; Fitzpatrick, S.; Cordon-Rosales, C.; Feliciangeli, D.; Beard, C.B. Molecular phylogeography of the Amazonian Chagas disease vectors Rhodnius prolixus and R. robustus. Mol. Ecol. 2003, 12, 997-1006. [CrossRef]

62. Pavan, M.G.; Monteiro, F.A. A multiplex PCR assay that separates Rhodnius prolixus from members of the Rhodnius robustus cryptic species complex (Hemiptera: Reduviidae). Trop. Med. Int. Health 2007, 12, 751-758. [CrossRef]

63. Abad-Franch, F.; Pavan, M.G.; Jaramillo-O., N.; Palomeque, F.S.; Dale, C.; Chaverra, D.; Monteiro, F.A. Rhodnius barretti, a new species of Triatominae (Hemiptera: Reduviidae) from western Amazonia. Mem. Inst. Oswaldo Cruz 2013, 108, 92-99. [CrossRef] [PubMed]

64. Carvalho, D.B.; Almeida, C.E.; Rocha, C.S.; Gardim, S.; Mendonça, V.J.; Ribeiro, A.R.; Alves, Z.C.P.V.T.; Ruellas, K.T.; Vedoveli, A.; da Rosa, J.A. A novel association between Rhodnius neglectus and the Livistona australis palm tree in an urban center foreshadowing the risk of Chagas disease transmission by vectorial invasions in Monte Alto City, São Paulo, Brazil. Acta Trop. 2014, 130, 35-38. [CrossRef] [PubMed]

65. de Meneguetti, D.U.O.; Soares, E.B.; Campaner, M.; Camargo, L.M.A. First report of Rhodnius montenegrensis (Hemiptera: Reduviidae: Triatominae) infection by Trypanosoma rangeli. Rev. Soc. Bras. Med. Trop. 2014, 47, 374-376. [CrossRef] [PubMed]

66. Souza, E.D.S.; Von Atzingen, N.C.B.; Furtado, M.B.; de Oliveira, J.; Nascimento, J.D.; Vendrami, D.P.; Gardim, S.; da Rosa, J.A. Description of Rhodnius marabaensis sp. n. (Hemiptera, Reduviidae, Triatominae) from Pará State, Brazil. Zookeys 2016, 45-62.

67. Valente, V.; Valente, S.; Ru, C.; Rocha, D.; Galvão, C.; Jurberg, J. Considerações Sobre Uma Nova Espécie Do Gênero Rhodnius Stâl, Do Estado Do Pará, Brasil [Hemiptera, Reduviidae, Triatominae]. Entomología y Vectores 2001, 8, 65-80.

68. da Rosa, J.A.; Justino, H.H.G.; Nascimento, J.D.; Mendonça, V.J.; Rocha, C.S.; de Carvalho, D.B.; Falcone, R.; de Azeredo-Oliveira, M.T.V.; Alevi, K.C.C.; de Oliveira, J. A new species of Rhodnius from Brazil (Hemiptera, Reduviidae, Triatominae). ZooKeys 2017, 675, 1-25. [CrossRef]

69. Nascimento, J.D.; da Rosa, J.A.; Salgado-Roa, F.C.; Hernández, C.; Pardo-Diaz, C.; Alevi, K.C.C.; Ravazi, A.; de Oliveira, J.; de Azeredo Oliveira, M.T.V.; Salazar, C.; et al. Taxonomical over splitting in the Rhodnius prolixus (Insecta: Hemiptera: Reduviidae) clade: Are, R. taquarussuensis (da Rosa et al., 2017) and R. neglectus (Lent, 1954) the same species? PLoS ONE 2019, 14, e0211285. [CrossRef] 
70. Cazorla, D. Revision of the vectors of Chagas disease in Venezuela [Hemiptera-Heteroptera, Reduviidae, Triatominae]. Saber 2016, 28, 387-470.

71. Matias, A.; de la Riva, J.; Martinez, E.; Torrez, M.; Dujardin, J.P. Domiciliation process of Rhodnius stali (Hemiptera: Reduviidae) in Alto Beni, La Paz, Bolivia. Trop. Med. Int. Health 2003, 8, 264-268. [CrossRef]

72. Jurberg, J.; da Rocha, D.S.; Galvão, C. Rhodnius zeledoni sp. nov. afim de Rhodnius paraensis Sherlock, Guitton \& Miles, 1977 (Hemiptera, Reduviidae, Triatominae). Biota Neotrop. 2009, 9, 123-128.

73. Neiva, A.; Pinto, C. Estado actual dos conhecimentos sobre o gênero Rhodnius Stal, com a descrição de uma nova espécie. Brasil-Médico 1923, 37, 20-24.

74. da Rosa, J.A.; Mendonça, V.J.; Gardim, S.; de Carvalho, D.B.; de Oliveira, J.; Nascimento, J.D.; Pinotti, H.; Pinto, M.C.; Cilense, M.; Galvão, C.; et al. Study of the external female genitalia of 14 Rhodnius species (Hemiptera, Reduviidae, Triatominae) using scanning electron microscopy. Parasit Vectors 2014, 7, 17. [CrossRef] [PubMed]

75. Nascimento, J.D.; Ribeiro, A.R.; Almeida, L.A.; de Oliveira, J.; Mendonça, V.J.; Cilense, M.; da Rosa, J.A. Morphology of the spermathecae of twelve species of Triatominae (Hemiptera, Reduviidae) vectors of Chagas disease. Acta Trop. 2017, 176, 440-445. [CrossRef] [PubMed]

76. dos Rodrigues, J.M.S.; da Rosa, J.A.; Moreira, F.F.F.; Galvão, C. Morphology of the terminal abdominal segments in females of Triatominae (Insecta: Hemiptera: Reduviidae). Acta Trop. 2018, 185, 86-97. [CrossRef] [PubMed]

77. Soto-Vivas, A.; Liria, J.; Luna, E. Geometric morphometrics and phylogeny in Rhodniini (Hemiptera, Reduviidae) of Venezuela. Acta Zool. Mex. 2011, 27, 87-102.

78. Ravazi, A.; Oliveira, J.; Rosa, J.A.; Azeredo-Oliveira, M.T.V.; Alevi, K.C.C. Spermiotaxonomy of the tribe Rhodniini (Hemiptera, Triatominae). Genet. Mol. Res. 2016, 15. [CrossRef] [PubMed]

79. Monteiro, F.A.; Wesson, D.M.; Dotson, E.M.; Schofield, C.J.; Beard, C.B. Phylogeny and molecular taxonomy of the Rhodniini derived from mitochondrial and nuclear DNA sequences. Am. J. Trop. Med. Hyg. 2000, 62, 460-465. [CrossRef]

80. Monteiro, F.A.; Lazoski, C.; Noireau, F.; Solé-Cava, A.M. Allozyme relationships among ten species of Rhodniini, showing paraphyly of Rhodnius including Psammolestes. Med. Vet. Entomol. 2002, 16, 83-90. [CrossRef]

81. Dias, F.B.S.; de Paula, A.S.; Belisário, C.J.; Lorenzo, M.G.; Bezerra, C.M.; Harry, M.; Diotaiuti, L. Influence of the palm tree species on the variability of Rhodnius nasutus Stål, 1859 (Hemiptera, Reduviidae, Triatominae). Infect. Genet. Evol. 2011, 11, 869-877. [CrossRef]

82. Dias, F.B.S.; Jaramillo-O., N.; Diotaiuti, L. Description and characterization of the melanic morphotype of Rhodnius nasutus Stål, 1859 (Hemiptera: Reduviidae: Triatominae). Rev. Soc. Bras. Med. Trop. 2014, 47, 637-641. [CrossRef]

83. Jurberg, J.; Rodrigues, J.M.S.; Moreira, F.F.F.; Dale, C.; Cordeiro, I.R.S.; Valdir, D.L., Jr.; Galvão, C.; Rocha, D.S. Atlas Iconográfico Dos Triatomíneos Do Brasil (Vetores Da Doença De Chagas); Instituto Oswaldo Cruz: Rio de Janeiro, Brasil, 2014.

84. Bérenger, J.; Pluot-Sigwalt, D. Rhodnius amazonicus Almeida, Santos \& Sposina, 1973, bona species, close to R. pictipes Stål, 1872 [Heteroptera, Reduviidae, Triatominae]. Mem. Inst. Oswaldo Cruz 2002, 97, 73-77. [PubMed]

85. Catalá, S.; Schofield, C. Antennal sensilla of Rhodnius: Antennal Sensilla of Rhodnius. J. Morphol. 1994, 219, 193-203. [CrossRef] [PubMed]

86. Panzera, F.; Pérez, R.; Hornos, S.; Panzera, Y.; Cestau, R.; Delgado, V.; Nicolini, P. Chromosome numbers in the Triatominae (Hemiptera-Reduviidae): A review. Mem. Inst. Oswaldo Cruz 1996, 91, 515-518. [CrossRef] [PubMed]

87. Panzera, F.; Pérez, R.; Panzera, Y.; Ferrandis, I.; Ferreiro, M.J.; Calleros, L. Cytogenetics and genome evolution in the subfamily Triatominae (Hemiptera, Reduviidae). Cytogenet. Genome Res. 2010, 128, 77-87. [CrossRef]

88. Genetics and Evolution of Infectious Diseases, 2nd ed.; Tibayrenc, M. (Ed.) Elsevier: Amsterdam, The Netherlands, 2017; ISBN 978-0-12-799942-5.

89. Alevi, K.C.C.; Ravazi, A.; Mendonça, V.J.; Rosa, J.A.; Azeredo-Oliveira, M.T.V. Karyotype of Rhodnius montenegrensis (Hemiptera, Triatominae). Genet. Mol. Res. 2015, 14, 222-226. [CrossRef]

90. Alevi, K.C.C.; da Costa Castro, N.F.; Lima, A.C.C.; Ravazi, A.; Morielle-Souza, A.; de Oliveira, J.; da Rosa, J.A.; de Azeredo Oliveira, M.T.V. Nucleolar persistence during spermatogenesis of the genus Rhodnius (Hemiptera, Triatominae). Cell. Biol. Int. 2014, 38, 977-980. [CrossRef] 
91. Madeira, F.F.; Borsatto, K.C.; Lima, A.C.C.; Ravazi, A.; de Oliveira, J.; da Rosa, J.A.; de Azeredo-Oliveira, M.T.V.; Alevi, K.C.C. Nucleolar Persistence: Peculiar Characteristic of Spermatogenesis of the Vectors of Chagas Disease (Hemiptera, Triatominae). Am. J. Trop. Med. Hyg. 2016, 95, 1118-1120. [CrossRef]

92. Gómez-Palacio, A.; Jaramillo-O., N.; Caro-Riaño, H.; Diaz, S.; Monteiro, F.A.; Pérez, R.; Panzera, F.; Triana, O. Morphometric and molecular evidence of intraspecific biogeographical differentiation of Rhodnius pallescens (Hemiptera: Reduviidae: Rhodniini) from Colombia and Panama. Infect. Genet. Evol. 2012, 12, 1975-1983. [CrossRef]

93. Panzera, F.; Ferrandis, I.; Ramsey, J.; Salazar-Schettino, P.M.; Cabrera, M.; Monroy, C.; Bargues, M.D.; Mas-Coma, S.; O'Connor, J.E.; Angulo, V.M.; et al. Genome size determination in chagas disease transmitting bugs (hemiptera-triatominae) by flow cytometry. Am. J. Trop. Med. Hyg. 2007, 76, 516-521. [CrossRef]

94. Pérez, R.; Panzera, F.; Page, J.; Suja, J.A.; Rufas, J.S. Meiotic behaviour of holocentric chromosomes: Orientation and segregation of autosomes in Triatoma infestans (Heteroptera). Chromosome Res. 1997, 5, 47-56. [CrossRef]

95. Panzera, Y.; Pita, S.; Ferreiro, M.J.; Ferrandis, I.; Lages, C.; Pérez, R.; Silva, A.E.; Guerra, M.; Panzera, F. High dynamics of rDNA cluster location in kissing bug holocentric chromosomes (Triatominae, Heteroptera). Cytogenet. Genome Res. 2012, 138, 56-67. [CrossRef] [PubMed]

96. Pita, S.; Panzera, F.; Ferrandis, I.; Galvao, C.; Gomez-Palacio, A.; Panzera, Y. Chromosomal divergence and evolutionary inferences in Rhodniini based on the chromosomal location of ribosomal genes. Mem. Inst. Oswaldo Cruz 2013, 108, 376-382. [CrossRef]

97. Panzera, F.; Dujardin, J.P.; Nicolini, P.; Caraccio, M.N.; Rose, V.; Tellez, T.; Bermúdez, H.; Bargues, M.D.; Mas-Coma, S.; O'Connor, J.E.; et al. Genomic changes of Chagas disease vector, South America. Emerg. Infect. Dis. 2004, 10, 438-446. [CrossRef] [PubMed]

98. Pérez, R.; Hernández, M.; Quintero, O.; Scvortzoff, E.; Canale, D.; Méndez, L.; Cohanoff, C.; Martino, M.; Panzera, F. Cytogenetic analysis of experimental hybrids in species of Triatominae (Hemiptera-Reduviidae). Genetica 2005, 125, 261-270. [CrossRef] [PubMed]

99. Oliveira, J.; Alevi, K.C.C.; Ravazi, A.; Herrera, H.M.; Santos, F.M.; de Azeredo-Oliveira, M.T.V.; da Rosa, J.A. New Evidence of the Monophyletic Relationship of the Genus Psammolestes Bergroth, 1911 (Hemiptera, Reduviidae, Triatominae). Am. J. Trop. Med. Hyg. 2018, 99, 1485-1488. [CrossRef] [PubMed]

100. Ravazi, A.; Alevi, K.C.C.; Oliveira, J.; Rosa, J.A.; Azeredo-Oliveira, M.T.V. Cytogenetic analysis in different populations of Rhodnius prolixus and R. nasutus from different countries of South America. Braz. J. Biol. 2018, 78, 183-185. [CrossRef] [PubMed]

101. Chavez, T.; Moreno, J.; Dujardin, J.P. Isoenzyme electrophoresis of Rhodnius species: A phenetic approach to relationships within the genus. Ann. Trop. Med. Parasitol. 1999, 93, 299-307. [CrossRef] [PubMed]

102. Lopez, G.; Moreno, J. Genetic variability and differentiation between populations of Rhodnius prolixus and R. pallescens, vectors of Chagas' Disease in Colombia. Mem. Inst. Oswaldo Cruz 1995, 90, 353-357. [CrossRef]

103. Dujardin, J.P.; Chavez, T.; Moreno, J.M.; Machane, M.; Noireau, F.; Schofield, C.J. Comparison of isoenzyme electrophoresis and morphometric analysis for phylogenetic reconstruction of the Rhodniini (Hemiptera: Reduviidae: Triatominae). J. Med. Entomol. 1999, 36, 653-659. [CrossRef]

104. Soares, R.P.; Sant'Anna, M.R.; Gontijo, N.F.; Romanha, A.J.; Diotaiuti, L.; Pereira, M.H. Identification of morphologically similar Rhodnius species (Hemiptera: Reduviidae: Triatominae) by electrophoresis of salivary heme proteins. Am. J. Trop. Med. Hyg. 2000, 62, 157-161. [CrossRef]

105. Harry, M. Isozymic data question the specific status of some blood-sucking bugs of the genus Rhodnius, vectors of Chagas disease. Trans. R. Soc. Trop. Med. Hyg. 1993, 87, 492. [CrossRef]

106. Solano, P.; Dujardin, J.; Schofield, C.; Romana, C.; Tibayrenc, M. Isoenzymes as a tool for the identification of Rhodnius species [Hemiptera:Reduviidae:Triatominae]. Res. Rev. Parasitol. 1996, 41-47.

107. Garcia, A.L.; Carrasco, H.J.; Schofield, C.J.; Stothard, J.R.; Frame, I.A.; Valente, S.A.; Miles, M.A. Random amplification of polymorphic DNA as a tool for taxonomic studies of triatomine bugs (Hemiptera: Reduviidae). J. Med. Entomol. 1998, 35, 38-45. [CrossRef] [PubMed]

108. Dujardin, J.P.; Muñoz, M.; Chavez, T.; Ponce, C.; Moreno, J.; Schofield, C.J. The origin of Rhodnius prolixus in Central America. Med. Vet. Entomol. 1998, 12, 113-115. [CrossRef]

109. Jaramillo, C.; Montaña, M.F.; Castro, L.R.; Vallejo, G.A.; Guhl, F. Differentiation and genetic analysis of Rhodnius prolixus and Rhodnius colombiensis by rDNA and RAPD amplification. Mem. Inst. Oswaldo Cruz 2001, 96, 1043-1048. [CrossRef] 
110. Soares, R.P.P.; Barbosa, S.E.; Borges, E.C.; Melo Júnior, T.A.; Romanha, A.J.; Dujardin, J.P.; Schofield, C.J.; Diotaiuti, L. Genetic Studies of Psammolestes tertius (Hemiptera: Reduviidae: Triatominae) Using Male Genital Morphology, Morphometry, Isoenzymes, and Random Amplified Polymorphic DNA. Biochem. Genet. 2001, 39, 1-13. [CrossRef]

111. Harry, M.; Roose, C.L.; Vautrin, D.; Noireau, F.; Romaña, C.A.; Solignac, M. Microsatellite markers from the Chagas disease vector, Rhodnius prolixus (Hemiptera, Reduviidae), and their applicability to Rhodnius species. Infect. Genet. Evol. 2008, 8, 381-385. [CrossRef]

112. Gómez-Sucerquia, L.J.; Triana-Chávez, O.; Jaramillo-Ocampo, N. Quantification of the genetic change in the transition of Rhodnius pallescens Barber, 1932 (Hemiptera: Reduviidae) from field to laboratory. Mem. Inst. Oswaldo Cruz 2009, 104, 871-877. [CrossRef]

113. Villacís, A.G.; Marcet, P.L.; Yumiseva, C.A.; Dotson, E.M.; Tibayrenc, M.; Brenière, S.F.; Grijalva, M.J. Pioneer study of population genetics of Rhodnius ecuadoriensis (Hemiptera: Reduviidae) from the central coastand southern Andean regions of Ecuador. Infect. Genet. Evol. 2017, 53, 116-127. [CrossRef]

114. Bargues, M.D.; Marcilla, A.; Dujardin, J.P.; Mas-Coma, S. Triatomine vectors of Trypanosoma cruzi: A molecular perspective based on nuclear ribosomal DNA markers. Trans. R. Soc. Trop. Med. Hyg. 2002, 96 (Suppl. S1), S159-S164. [CrossRef]

115. de Paula, A.S.; Diotaiuti, L.; Schofield, C.J. Testing the sister-group relationship of the Rhodniini and Triatomini (Insecta: Hemiptera: Reduviidae: Triatominae). Mol. Phylogenet. Evol. 2005, 35, 712-718. [CrossRef] [PubMed]

116. Díaz, S.; Triana-Chávez, O.; Gómez-Palacio, A. The nuclear elongation factor-1 $\alpha$ gene: A promising marker for phylogenetic studies of Triatominae (Hemiptera: Reduviidae). Infect. Genet. Evol. 2016, 43, 274-280. [CrossRef] [PubMed]

117. Hypsa, V.; Tietz, D.F.; Zrzavý, J.; Rego, R.O.M.; Galvao, C.; Jurberg, J. Phylogeny and biogeography of Triatominae (Hemiptera: Reduviidae): Molecular evidence of a New World origin of the Asiatic clade. Mol. Phylogenet. Evol. 2002, 23, 447-457. [CrossRef]

118. Lyman, D.F.; Monteiro, F.A.; Escalante, A.A.; Cordon-Rosales, C.; Wesson, D.M.; Dujardin, J.P.; Beard, C.B. Mitochondrial DNA sequence variation among triatomine vectors of Chagas' disease. Am. J. Trop. Med. Hyg. 1999, 60, 377-386. [CrossRef] [PubMed]

119. Stothard, J.R.; Yamamoto, Y.; Cherchi, A.; Garcia, A.L.; Valente, S.A.S.; Schofield, C.J.; Miles, M.A. A preliminary survey of mitochondrial sequence variation in Triatominae (Hemiptera: Reduviidae) using polymerase chain reaction-based single strand conformational polymorphism (SSCP) analysis and direct sequencing. Bull. Entomol. Res. 1998, 88, 553-560. [CrossRef]

120. Hwang, W.S.; Weirauch, C. Evolutionary history of assassin bugs (insecta: Hemiptera: Reduviidae): Insights from divergence dating and ancestral state reconstruction. PLoS ONE 2012, 7, e45523. [CrossRef] [PubMed]

121. Justi, S.; Russo, C.A.M.; Mallet, J.; Obara, M.; Galvão, C. Molecular phylogeny of Triatomini (Hemiptera: Reduviidae: Triatominae). Parasit. Vectors 2014, 7, 149. [CrossRef]

122. Justi, S.A.; Galvão, C.; Schrago, C.G. Geological Changes of the Americas and their Influence on the Diversification of the Neotropical Kissing Bugs (Hemiptera: Reduviidae: Triatominae). PLoS Negl. Trop. Dis. 2016, 10, e0004527. [CrossRef]

123. Patterson, J.S.; Gaunt, M.W. Phylogenetic multi-locus codon models and molecular clocks reveal the monophyly of haematophagous reduviid bugs and their evolution at the formation of South America. Mol. Phyl. Evol. 2010, 56, 608-621. [CrossRef]

124. Weirauch, C.; Munro, J.B. Molecular phylogeny of the assassin bugs (Hemiptera: Reduviidae), based on mitochondrial and nuclear ribosomal genes. Mol. Phyl. Evol. 2009, 53, 287-299. [CrossRef]

125. Zhang, J.; Gordon, E.R.L.; Forthman, M.; Hwang, W.S.; Walden, K.; Swanson, D.R.; Johnson, K.P.; Meier, R.; Weirauch, C. Evolution of the assassin's arms: Insights from a phylogeny of combined transcriptomic and ribosomal DNA data (Heteroptera: Reduvioidea). Sci. Rep. 2016, 6, 22177. [CrossRef] [PubMed]

126. Márquez, E.; Jaramillo-O., N.; Gómez-Palacio, A.; Dujardin, J.-P. Morphometric and molecular differentiation of a Rhodnius robustus-like form from R. robustus Larousse, 1927 and R. prolixus Stal, 1859 (Hemiptera, Reduviidae). Acta Trop. 2011, 120, 103-109. [CrossRef] [PubMed]

127. de Paula, A.S.; Diotaiuti, L.; Galvão, C. Systematics and biogeography of Rhodniini (Reduvioidea: Reduviidae: Triatominae) based on $16 \mathrm{~S}$ mitochondrial rDNA sequences. J. Biogeogr. 2007, 34, 699-712. [CrossRef] 
128. Maia Da Silva, F.; Junqueira, A.C.V.; Campaner, M.; Rodrigues, A.C.; Crisante, G.; Ramirez, L.E.; Caballero, Z.C.E.; Monteiro, F.A.; Coura, J.R.; Añez, N.; et al. Comparative phylogeography of Trypanosoma rangeli and Rhodnius (Hemiptera: Reduviidae) supports a long coexistence of parasite lineages and their sympatric vectors. Mol. Ecol. 2007, 16, 3361-3373. [CrossRef]

129. Wiens, J.J.; Tiu, J. Highly incomplete taxa can rescue phylogenetic analyses from the negative impacts of limited taxon sampling. PLoS ONE 2012, 7, e42925. [CrossRef]

130. Díaz, S.; Panzera, F.; Jaramillo-O., N.; Pérez, R.; Fernández, R.; Vallejo, G.; Saldaña, A.; Calzada, J.E.; Triana, O.; Gómez-Palacio, A. Genetic, Cytogenetic and Morphological Trends in the Evolution of the Rhodnius (Triatominae: Rhodniini) Trans-Andean Group. PLoS ONE 2014, 9, e87493. [CrossRef]

131. Abad-Franch, F.; Monteiro, F.A. Biogeography and evolution of Amazonian triatomines (Heteroptera: Reduviidae): Implications for Chagas disease surveillance in humid forest ecoregions. Mem. Inst. Oswaldo Cruz 2007, 102 (Suppl. S1), S57-S70. [CrossRef]

132. Pavan, M.G.; Mesquita, R.D.; Lawrence, G.G.; Lazoski, C.; Dotson, E.M.; Abubucker, S.; Mitreva, M.; Randall-Maher, J.; Monteiro, F.A. A nuclear single-nucleotide polymorphism (SNP) potentially useful for the separation of Rhodnius prolixus from members of the Rhodnius robustus cryptic species complex (Hemiptera: Reduviidae). Infect. Genet. Evol. 2013, 14, 426-433. [CrossRef]

133. Barret, T. Species interfertility and crossing experiments in triatomine systematics. In Proceedings of the International Workshop on Population Genetics and Control of Triatominae, Santo Domingo de los Colorados, Ecuador, 24-28 September 1995; pp. 72-77.

134. Monteiro, F.A.; Escalante, A.A.; Beard, C.B. Molecular tools and triatomine systematics: A public health perspective. Trends Parasitol. 2001, 17, 344-347. [CrossRef]

135. Da Rosa, J.; Solano, C.; Gardim, S.; Pinto, M.; Mendoca, V.; Rente, J. Description of Rhodnius montenegrensis n. sp. [Hemiptera: Reduviidae: Triatominae] from the state of Rondônia, Brazil. Zootaxa 2012, 3478, 62-76. [CrossRef]

136. Mesquita, R.D.; Vionette-Amaral, R.J.; Lowenberger, C.; Rivera-Pomar, R.; Monteiro, F.A.; Minx, P.; Spieth, J.; Carvalho, A.B.; Panzera, F.; Lawson, D.; et al. Genome of Rhodnius prolixus, an insect vector of Chagas disease, reveals unique adaptations to hematophagy and parasite infection. Proc. Natl. Acad. Sci. USA 2015, 112, 14936-14941. [CrossRef] [PubMed]

137. Pita, S.; Mora, P.; Vela, J.; Palomeque, T.; Sánchez, A.; Panzera, F.; Lorite, P. Comparative Analysis of Repetitive DNA between the Main Vectors of Chagas Disease: Triatoma infestans and Rhodnius prolixus. Int. J. Mol. Sci. 2018, 19, 1277. [CrossRef] [PubMed]

138. Zhao, Y.; Jiang, M.; Wu, Y.; Song, F.; Cai, W.; Li, H. Mitochondrial genomes of three kissing bugs (Reduviidae: Triatominae) and their phylogenetic implications. Int. J. Biol. Macromol. 2019, 134, 36-42. [CrossRef] [PubMed]

139. Medeiros, M.N.; Logullo, R.; Ramos, I.B.; Sorgine, M.H.F.; Paiva-Silva, G.O.; Mesquita, R.D.; Machado, E.A.; Coutinho, M.A.; Masuda, H.; Capurro, M.L.; et al. Transcriptome and gene expression profile of ovarian follicle tissue of the triatomine bug Rhodnius prolixus. Insect Biochem. Mol. Biol. 2011, 41, 823-831. [CrossRef]

140. Ribeiro, J.M.C.; Genta, F.A.; Sorgine, M.H.F.; Logullo, R.; Mesquita, R.D.; Paiva-Silva, G.O.; Majerowicz, D.; Medeiros, M.; Koerich, L.; Terra, W.R.; et al. An insight into the transcriptome of the digestive tract of the bloodsucking bug, Rhodnius prolixus. PLoS Negl. Trop. Dis. 2014, 8, e2594. [CrossRef]

141. Latorre-Estivalis, J.M.; Robertson, H.M.; Walden, K.K.O.; Ruiz, J.; Gonçalves, L.O.; Guarneri, A.A.; Lorenzo, M.G. The molecular sensory machinery of a Chagas disease vector: Expression changes through imaginal moult and sexually dimorphic features. Sci. Rep. 2017, 7, 40049. [CrossRef]

142. Traverso, L.; Lavore, A.; Sierra, I.; Palacio, V.; Martinez-Barnetche, J.; Latorre-Estivalis, J.M.; Mougabure-Cueto, G.; Francini, F.; Lorenzo, M.G.; Rodríguez, M.H.; et al. Comparative and functional triatomine genomics reveals reductions and expansions in insecticide resistance-related gene families. PLoS Negl. Trop. Dis. 2017, 11, e0005313. [CrossRef]

143. de Carvalho, D.B.; Congrains, C.; Chahad-Ehlers, S.; Pinotti, H.; de Brito, R.A.; da Rosa, J.A. Differential transcriptome analysis supports Rhodnius montenegrensis and Rhodnius robustus (Hemiptera, Reduviidae, Triatominae) as distinct species. PLoS ONE 2017, 12, e0174997. [CrossRef]

144. Castro, M.R.J.; Goubert, C.; Monteiro, F.A.; Vieira, C.; Carareto, C.M.A. Homology-Free Detection of Transposable Elements Unveils Their Dynamics in Three Ecologically Distinct Rhodnius Species. Genes 2020, 11, 170. [CrossRef] 
145. Dos Santos Souza, É.; Fernandes, R.P.; Guedes, W.N.; Dos Santos, F.N.; Eberlin, M.N.; Lopes, N.P.; Padovani, V.D.; da Rosa, J.A. Rhodnius spp. are differentiated based on the peptide/protein profile by matrix-assisted laser desorption/ionization mass spectrometry and chemometric tools. Anal. Bioanal. Chem. 2020, 412, 1431-1439. [CrossRef]

146. Dayrat, B. Towards integrative taxonomy. Biol. J. Linn. Soc. 2005, 85, 407-415. [CrossRef]

147. Weirauch, C. Cladistic analysis of Reduviidae (Heteroptera: Cimicomorpha) based on morphological characters. Syst. Entomol. 2008, 33, 229-274. [CrossRef]

148. Perlowagora-Szumlewicz, A. Induction of male sterility through manipulation of genetic mechanisms present in vector species of Chagas disease. (Remarks on integrating sterile-male release with insecticidal control measures against vectors of Chagas disease). Rev. Inst. Med. Trop. Sao Paulo 1972, 14, 360-371. [PubMed]

149. Mas-Coma, S.; Bargues, M.D. Populations, hybrids and the systematic concepts of species and subspecies in Chagas disease triatomine vectors inferred from nuclear ribosomal and mitochondrial DNA. Acta Trop. 2009, 110, 112-136. [CrossRef] [PubMed]

150. Herrando-Moraira, S.; Calleja, J.A.; Galbany-Casals, M.; Garcia-Jacas, N.; Liu, J.-Q.; López-Alvarado, J.; López-Pujol, J.; Mandel, J.R.; Massó, S.; Montes-Moreno, N.; et al. Nuclear and plastid DNA phylogeny of tribe Cardueae (Compositae) with Hyb-Seq data: A new subtribal classification and a temporal diversification framework. Mol. Phyl. Evol. 2019, 137, 313-332. [CrossRef]

151. Johnson, K.P.; Dietrich, C.H.; Friedrich, F.; Beutel, R.G.; Wipfler, B.; Peters, R.S.; Allen, J.M.; Petersen, M.; Donath, A.; Walden, K.K.O.; et al. Phylogenomics and the evolution of hemipteroid insects. Proc. Natl. Acad. Sci. USA 2018, 115, 12775-12780. [CrossRef]

(C) 2020 by the authors. Licensee MDPI, Basel, Switzerland. This article is an open access article distributed under the terms and conditions of the Creative Commons Attribution (CC BY) license (http://creativecommons.org/licenses/by/4.0/). 